\title{
Environmental controls over methanol emission from leaves
}

\author{
P. Harley ${ }^{1}$, J. Greenberg ${ }^{1}$, Ü. Niinemets ${ }^{2}$, and A. Guenther ${ }^{1}$ \\ ${ }^{1}$ Atmospheric Chemistry Division, National Center for Atmospheric Research, Boulder, Colorado, USA \\ ${ }^{2}$ Institute of Agricultural and Environmental Sciences, Estonian University of Life Sciences, Tartu, Estonia
}

Received: 31 July 2007 - Published in Biogeosciences Discuss.: 6 August 2007

Revised: 5 November 2007 - Accepted: 20 November 2007 - Published: 5 December 2007

\begin{abstract}
Methanol is found throughout the troposphere, with average concentrations second only to methane among atmospheric hydrocarbons. Proposed global methanol budgets are highly uncertain, but all agree that at least $60 \%$ of the total source arises from the terrestrial biosphere and primary emissions from plants. However, the magnitude of these emissions is also highly uncertain, and the environmental factors which control them require further elucidation.

Using a temperature-controlled leaf enclosure, we measured methanol emissions from leaves of six plant species by proton transfer reaction mass spectrometry, with simultaneous measurements of leaf evapotranspiration and stomatal conductance. Rates of emission at $30^{\circ} \mathrm{C}$ varied from 0.2 to $38 \mu \mathrm{gg}$ (dry mass) ${ }^{-1} \mathrm{~h}^{-1}$, with higher rates measured on young leaves, consistent with the production of methanol via pectin demethylation in expanding foliage. On average, emissions increased by a factor of 2.3 for each $10^{\circ} \mathrm{C}$ increase in leaf temperature. At constant temperature, emissions were also correlated with co-varying incident photosynthetic photon flux density and rates of stomatal conductance. The data were analyzed using the emission model developed by $\mathrm{Ni}$ inemets and Reichstein (2003a, b), with the incorporation of a methanol production term that increased exponentially with temperature. It was concluded that control of emissions, during daytime, was shared by leaf temperature and stomatal conductance, although rates of production may also vary diurnally in response to variations in leaf growth rate in expanding leaves. The model, which generally provided reasonable simulations of the measured data during the day, significantly overestimated emissions on two sets of measurements made through the night, suggesting that production rates of methanol were reduced at night, perhaps because leaf growth was reduced or possibly through a direct effect of light on production. Although the short-term dynamics
\end{abstract}

Correspondence to: P. Harley

(harley@ucar.edu) of methanol emissions can be successfully modeled only if stomatal conductance and compound solubility are taken into account, emissions on longer time scales will be determined by rates of methanol production, controls over which remain to be investigated.

\section{Introduction}

In the last decade, development of new instrumentation has fostered the measurement of oxygenated volatile organic compounds (OVOC) in the troposphere. Singh et al. (1995) measured significant quantities of OVOC over the Pacific, dominated by methanol ( 400 to $700 \mathrm{ppt}$ ) and acetone (200 to $500 \mathrm{ppt}$ ). Intensive aircraft measurements in the last decade have confirmed the magnitude of methanol, average concentrations of which are second only to $\mathrm{CH}_{4}$ among atmospheric hydrocarbons. Concentrations in the remote troposphere range from 0.1 to $1.1 \mathrm{ppbv}$ (Heikes et al., 2002; Singh et al., 2004), with values in the continental boundary layer up to 10 times higher. Methanol oxidation is a significant source of formaldehyde in the remote troposphere and the continental boundary layer, as well as carbon monoxide (4-6\% of the global total). It is thought to play a small but significant role in the tropospheric oxidant balance, reducing tropospheric levels of hydroxyl radical by approx. 2\% (Tie et al., 2003), although proposed heterogeneous reactions involving methanol and the hydroxyl radical (Tabadazeh et al., 2004) would enhance its importance. Jacob et al. (2005) suggested "a minor but non-negligible role for methanol in global tropospheric chemistry".

A number of investigators have attempted to construct annual global budgets for methanol (Singh et al., 2000; Heikes et al., 2002; Galbally and Kirstine, 2002; Tie et al., 2003; von Kuhlmann et al., 2003; summarized in Jacob et al., 2005). Considerable uncertainties remain with respect to both sources and sinks, resulting in a wide range of global

Published by Copernicus Publications on behalf of the European Geosciences Union. 
estimates, and varying degrees of budget closure. Mean estimates of total source strength in these studies range from 122 to $350 \mathrm{Tg}^{-1}$, while those of total sinks range from 40 to $270 \mathrm{Tg}^{-1}$. A similar range of variation is associated with the magnitude of the methanol source arising from direct emissions from living plant biomass, with mean estimates ranging from 75 to $280 \mathrm{Tg}^{-1}$. In all cases, however, direct emissions from plants constituted the major source of methanol to the atmosphere, ranging from 60 to $80 \%$ of the total source strength. This value is consistent with the results of Shim et al. (2007) who applied the positive matrix factorization method to chemical concentration measurements made during two aircraft campaigns over the Pacific Ocean (TRACE-P and PEM-Tropics B), and assigned $80-88 \%$ of the measured methanol to their "terrestrial biogenic" factor.

Methanol comprises a significant fraction of the total VOC emissions measured above a variety of different ecosystems, generally exceeding emissions of all other VOC except terpenoids. Using a variety of techniques (static enclosures, relaxed eddy accumulation, eddy covariance), canopy-scale fluxes of methanol have been measured above grasslands (Fukui and Doskey, 1998; Kirstine et al., 1998; Brunner et al., 2007), crops (Das et al., 2003; Warneke et al., 2002; Custer and Schade, 2007), coniferous forests (Baker et al., 2001; Karl et al., 2002), pine plantations (Schade and Goldstein, 2001; Karl et al., 2005), deciduous temperate forests (Karl et al., 2003; Spirig et al., 2005), and tropical forests (Geron et al., 2002; Karl et al., 2004). Results from these studies are summarized in Seco et al. (2007).

The major source of methanol from plants appears to be its release in the demethylation of pectin during cell wall expansion, a reaction catalyzed by the enzyme pectin methylesterase (PME) (Galbally and Kirstine, 2002). Supporting evidence is provided by recent isotope studies (Keppler et al., 2004) in which the methoxyl groups of pectin (and lignin) were shown to be exceptionally depleted in ${ }^{13} \mathrm{C}$. Methanol emitted by plants was also anomalously depleted in ${ }^{13} \mathrm{C}$, to approx. the same extent, strongly suggesting that the methoxyl pool associated with pectin is the predominant source. Pectin is the major source of methanol from living biomass, but both pectin and lignin are expected to contribute to methanol emissions from soil litter (Fall and Benson, 1996) and biomass burning. It was recently demonstrated that PME activity in Salvia was stimulated by caterpillar oral secretions, resulting in large increases in methanol emission (von Dahl et al., 2006). Methanol may also be released during protein repair, but this probably represents a minor source (Fall and Benson, 1996). Potential sinks for methanol in or on the leaf include oxidation to formaldehyde (Gout et al., 2000) and metabolism by methylotrophic bacteria which colonize leaves of many species in high numbers and can exist solely on a methanol diet (Holland and Polacco, 1994). Neither of these potential sinks has been quantified, but both are assumed to be small (Galbally and Kirstine, 2002).
The first quantitative estimates of methanol emissions from plants were presented by MacDonald and Fall (1993). Emission rates from mature leaves of 14 species of trees, measured at $30^{\circ} \mathrm{C}$, varied substantially, ranging from $1.5 \mu \mathrm{g} \mathrm{g}^{-1} \mathrm{~h}^{-1}$ to $15 \mu \mathrm{g} \mathrm{g}^{-1} \mathrm{~h}^{-1}$. Highest rates (2.2 to $46 \mu \mathrm{g} \mathrm{g}^{-1} \mathrm{~h}^{-1}$ ) were obtained from a variety of crop species. On average, rates were twice as high in young leaves. Several fold higher emissions from developing vs. mature leaves of cotton (Gossypium hirsutum), cottonwood (Populus deltoides) and European beech (Fagus sylvatica) were reported by Hüve et al. (2007), who also demonstrated in an elegant study that integrated daily emissions of methanol from Populus leaves were strongly correlated with total daily leaf growth.

Until recently, little has been published on the environmental controls over methanol emission from plants. MacDonald and Fall (1993) observed that methanol emissions were influenced by rapid changes in stomatal conductance $\left(\mathrm{g}_{s}\right)$. This behavior was confirmed by Nemecek-Marshall et al. (1995), who also observed large bursts of methanol following dark/light transitions, as did Hüve et al. (2007). By contrast, VOC such as isoprene or $\alpha$-pinene are unaffected by large and rapid decreases in stomatal conductance (Fall and Monson 1992). This apparent anomaly was explained by Niinemets and Reichstein (2003a) who developed a model of VOC emission from plants that incorporates effects of compound solubility and successfully explains the observed differential responses of various VOC to stomatal closure.

The model, exhaustively described previously (Niinemets and Reichstein, 2002, 2003a, b) assumes that methanol is produced at some prescribed rate in the cell walls. It diffuses in the liquid phase along a series of diffusion pathways until it reaches the outer surface of the cell walls and the interface between aqueous and gas phases. At that point, liquid to gas phase partitioning is determined by $H$, the Henry constant for methanol. Methanol in the gas phase diffuses into the substomatal cavity and then through the stomata and leaf boundary layer to the ambient air. Diffusion of gas phase methanol from the intercellular air space to the air outside the leaf boundary layer, i.e., the rate of emission, follows Fick's law, and is proportional to the methanol partial pressure difference and the total gas phase conductance.

Assuming constant rates of VOC production, any change in $\mathrm{g}_{s}$ is countered by corresponding, but opposite, changes in the gas and liquid pools, resulting in a change in the partial pressure gradient exactly proportional, but opposite in sign, to the change in conductance. Hence, there is no alteration in the methanol flux. For largely insoluble isoprene $\left(H @ 25^{\circ} \mathrm{C}=7780 \mathrm{~Pa} \mathrm{~m}^{3} \mathrm{~mol}^{-1}\right)$ and $\alpha$ pinene $\left(H @ 25^{\circ} \mathrm{C}=10840 \mathrm{~Pa} \mathrm{~m}^{3} \mathrm{~mol}^{-1}\right)$, a new steady-state gas pool is re-established in a matter of seconds following any perturbation (Niinemets and Reichstein, 2003a) and stomata cannot limit the flux (Fall and Monson, 1992; Loreto et al., 1996). However, highly soluble methanol ( $H @ 25^{\circ} \mathrm{C}=0.461 \mathrm{~Pa} \mathrm{~m}^{3} \mathrm{~mol}^{-1}$ ) partitions strongly into the 
liquid phase, and a large increase in liquid pool size following stomatal closure is required before gas partial pressures rise sufficiently to completely counteract the reduced conductance. Once a new equilibrium is reached, the original flux is restored, but during this extended transition period to a new equilibrium state, stomata may have a significant impact on observed emissions.

All other things being equal, the extent to which stomata limit the flux of a given VOC is determined largely by $H$. However, several other factors can also influence the time needed for re-equilibration of the leaf pools, helping to explain observed differences in stomatal sensitivity between species or for a given leaf at different times. As shown by Niinemets and Reichstein (2003b), the time for re-equilibration is affected slightly by the magnitude of various liquid and gas phase resistances within the leaf, and more significantly by the amount of liquid water within the leaf into which methanol can partition. As the amount of water increases, the time needed for pool equilibration also increases. The time needed for re-equilibration of the liquid methanol pool also increases as values of $\mathrm{g}_{s}$ decline; i.e., leaves with lower rates of stomatal conductance spend more time in non-steady state situations, and methanol emissions are more likely to be limited by $\mathrm{g}_{s}$. Thus, the extent to which changes in stomatal conductance affect emissions is influenced by the magnitude of stomatal conductance, the rate at which stomata open or close, and by internal leaf anatomy, which determines resistances to intercellular diffusion in both gas and liquid phase, and also establishes the potential liquid pool size.

The detailed model of Niinemets and Reichstein treats these factors explicitly, and short-term patterns of emissions are generally well described through the interaction of methanol production rate, changes in the size of liquid and gas phase pools, and stomatal conductance. Comparison between measured emission data and model predictions provided convincing evidence that high solubility plays the key role in explaining stomatal sensitivity of methanol emissions. However, the data against which their model was tested were obtained under constant temperature and light, and in their simulations, both methanol production rates and stomatal conductance were prescribed. If one wishes to model methanol emissions under naturally occurring conditions, it becomes necessary to predict rates of methanol production as well. In available methanol emission models, however, neither production rates nor variation in stomatal conductance are well characterized.

The major goal of this paper is to establish the relative importance of leaf temperature and incident photosynthetic photon flux density (PPFD) on methanol production, and the importance of stomatal conductance in controlling emissions under varying light and temperature conditions. We first present representative examples of leaf-level methanol emission data obtained from several plant species under a wide range of light and temperature conditions along with stomatal conductance data collected concurrently. Since stomatal conductance itself varies in response to PPFD and temperature, separating the direct effects of these drivers on methanol production from indirect effects via changes in stomatal conductance is challenging. To facilitate this process, we evaluate the data sets against predictions of the model developed by Niinemets and Reichstein (2002, 2003a, b) and assess the suitability of the model for predicting methanol emissions under a range of environmental conditions.

\section{Methods}

Emissions of methanol were investigated in six plant species: two conifers, two broadleaved trees and two grasses. Individual saplings of loblolly pine (Pinus taeda) and grey pine (P. sabiniana) were obtained from Forest Farm Nursery (Williams, OR) and those of mango (Mangifera indica) were obtained from Pine Island Nursery (Miami, FL). Young plants of cottonwood (Populus deltoides [S7c8 East Texas Day Neutral clone]) were generated from greenwood cuttings taken from established plants growing in the Univ. of Colorado greenhouse. Plants of sorghum-sudangrass (Sorghum bicolor) and fescue (Festuca sp.) were grown from seed (Rocky Mountain Seed Co, Denver CO). Plants were repotted into 4-L plastic pots containing a commercial potting mix (MiracleGro) and maintained in the NCAR Frost Phytotron. Osmocote slow release fertilizer was applied to pots of all trees, and the grasses were fertilized monthly with Peter's Professional Plant Food (20N-20P-20K).

Intact leaves or needles were enclosed in a flow-through, temperature-controlled, fan-stirred leaf cuvette (MPH-1000, Campbell Scientific, Logan, UT), while the rest of the plant experienced laboratory conditions of relatively low light and approximately $20^{\circ} \mathrm{C}$. Air entering the $400 \mathrm{ml}$ cuvette consisted of zero air (Model 737, Pure Air Generator, AADCO Instruments, Inc., Clearwater, FL), further purified by flowing through a palladium catalyst maintained at $300^{\circ} \mathrm{C}$, and mixed with $1 \% \mathrm{CO}_{2}$ in air to a final $\mathrm{CO}_{2}$ concentration of approximately $400 \mathrm{ppm}$. Incoming air was humidified to the desired dew point by routing a fraction of the zero air through a glass bubbler containing de-ionized water. All mixing flows were controlled using mass flow controllers (Model 825, Edwards High Vacuum International, Wilmington, MA) and the flow rate of air entering the cuvette was measured with a mass flow meter (Model 831, Edwards High Vacuum International). Leaf or chamber temperature was controlled $\left( \pm 0.3^{\circ} \mathrm{C}\right)$ using thermoelectric coolers, and light was provided by a $1000-\mathrm{W}$ high intensity metal halide discharge lamp (Sylvania MS1000-M47). $\mathrm{CO}_{2}$ and $\mathrm{H}_{2} \mathrm{O}$ vapor in air exiting the leaf cuvette were measured by infrared gas analyzer (LI-6262, Li-Cor, Lincoln, NE) and a portion of the air was directed to the inlet of a proton transfer reaction mass spectrometer (PTR-MS) for analysis of methanol. After being measured, plant tissue inside the cuvette was excised. For broad-leaved species and grasses, leaf area was 
estimated by tracing the leaf outline onto construction paper of known mass per unit area $\left(\mathrm{g} \mathrm{m}^{-2}\right)$ and then cutting and weighing the outline. For all species, measured leaf tissue was oven-dried $\left(70^{\circ} \mathrm{C}\right)$ for a minimum of $24 \mathrm{~h}$ and dry mass (g) determined. Experimental leaves were not sterilized, and the potential impact of methylotrophic bacteria residing on the leaf surface was not considered.

Methanol concentrations were measured using proton transfer reaction mass spectrometry (PTR-MS). The PTRMS used in this study, designed and built at NCAR and fully described in Hanson et al. (2003), consists of an ion source (a radioactive strip of ${ }^{241} \mathrm{Am}$ [NRD Incorporated, Grand Island, NY]), a drift tube $8.8 \mathrm{~cm}$ in length, and a mass selective quadrupole detector. Hydronium ions $\left(\mathrm{H}_{3} \mathrm{O}^{+}\right)$served as reagent ions. As sample air passes through a drift tube, those VOC with a greater proton affinity than $\mathrm{H}_{3} \mathrm{O}^{+}$accept a proton and are passed on to the quadrupole mass detector. This PTR-MS was designed to operate at higher drift tube pressures $(\approx 10$ Torr) than commercially available PTR-MS systems, conferring increased sensitivity (Hanson et al., 2003).

When normalized to $1 \mathrm{MHz}$ of primary reagent signal, PTR-MS sensitivity to a given target compound remains constant as long as the geometry of the drift tube and operating conditions are unchanged. However, over the course of these experiments, slight modifications in the operating conditions of the PTR-MS were carried out in an attempt to optimize performance. As a result, daily calibrations were carried out, using a high-pressure cylinder prepared gravimetrically at NCAR and containing $4.0 \mathrm{ppmv}( \pm 5 \%)$ methanol. Air from the high concentration standard was serially diluted using humidified zero air to generate a final concentration of $27 \mathrm{ppbv}$. A calibration using this diluted standard was carried out at least once a day. As noted in Hanson et al. (2003), the sensitivity to methanol decreases with humidity, presumably due to back reactions (i.e., proton transfer back to $\mathrm{H}_{3} \mathrm{O}^{+}$) at high humidities. Several calibrations over the course of the experiment were carried out while varying the dew point of the calibration stream, allowing us to develop an empirical vapor pressure correction for methanol sensitivity. Vapor pressures in the experiments reported here varied over the range 9 to 21 mbar, resulting in a $23 \%$ variation in sensitivity to methanol.

Initial tests of the integrated leaf cuvette and PTR-MS system indicated background concentrations of methanol significantly greater than zero. These background levels decreased gradually over time, and maintaining a flow of zero air through the cuvette at all times kept these background levels to a minimum. Despite these precautions, background levels could not be neglected. Thus, for all data reported below, following removal of an experimental leaf, the methanol signal arising from the empty cuvette was recorded and subtracted from all leaf measurements. At $30^{\circ} \mathrm{C}$, this correction averaged approximately 200 pptv.

Rates of transpiration, stomatal conductance $\left(\mathrm{g}_{s}\right)$ and methanol emission were calculated based on concentra- tion difference between air entering and leaving the cuvette $\left(\mathrm{nmol} \mathrm{mol}{ }^{-1}\right)$ and the flow rate through the enclosure $\left(\mathrm{mol} \mathrm{s}^{-1}\right)$, corrected for the increased mass flow exiting the chamber due to transpiration (von Caemmerer and Farquhar, 1981). All methanol emission rates are expressed on a per unit dry mass basis $\left(\mu \mathrm{g}\right.$ methanol $\mathrm{g}^{-1}$ dry mass $\mathrm{h}^{-1}$ ), but values of leaf mass per unit area (LMA, $\mathrm{g} \mathrm{m}^{-2}$ ) are provided for broad-leaved species (Table 1) to allow conversion to area based units. Rates of stomatal conductance and rates of transpiration are expressed as $\mathrm{mmol} \mathrm{H}_{2} \mathrm{O} \mathrm{m}^{-2} \mathrm{~s}^{-1}$ and mmol $\mathrm{H}_{2} \mathrm{O} \mathrm{g}^{-1} \mathrm{~h}^{-1}$ for broad-leaved species and pines, respectively.

We chose to evaluate our data in the context of the VOC emissions model developed by Niinemets and Reichstein, parameterized specifically for methanol. Full parameterization of the Niinemets-Reichstein model requires assigning values to a large number of parameters describing internal leaf anatomy, gas and liquid phase conductance pathways within the leaf, and physico-chemical characteristics of the compound of interest. To describe the physico-chemical characteristics of methanol, we use the values and temperature dependencies given in Niinemets and Reichstein (2003b). Leaf anatomy and internal diffusion pathways vary between vegetation species. Lacking detailed anatomical information, we used published parameterizations (Niinemets and Reichstein, 2003b), that of Pinus sylvestris for our two pine species, and that of Phaseolus vulgaris for the grasses. Rather than use the parameterization developed for Quercus ilex, a mediterranean sclerophyllous tree, we follow the example of $\mathrm{Ni}$ inemets and Reichstein (2003a), and use averaged anatomical characteristics of $Q$. ilex and Phaseolus as the default parameterization for our broadleaf trees, mango and cottonwood. While we recognize that none of these represents a perfect match for the species under consideration, sensitivity analyses (Niinemets and Reichstein, 2003b) demonstrated that large differences in most leaf anatomical features had only a minor effect on model behavior. The major exception is the size of the water pool into which methanol partitions, which has a large impact on the magnitude of emission bursts and influences the time needed for the liquid pool to equilibrate and thus the extent to which stomata limit emissions.

The Niinemets-Reichstein model has not heretofore incorporated variations in the rate of production, controls over which are not well characterized, either in the short-term (minutes) or over periods of hours to days. Data presented below indicate that methanol emissions increase exponentially with leaf temperature (Fig. 5), and we assume that this reflects the temperature dependence of methanol production. Production $\left(P_{m}\right)$ in the model is assumed to increase exponentially,

$P_{m}=P_{m 30} \times \exp ^{(\beta *[\text { Tleaf }-30])}$

where $P_{m 30}$ is the rate of methanol production at $30^{\circ} \mathrm{C}$ and the rate of exponential increase is determined by the value 
Table 1. Summary of leaf-level measurements carried out during this study. Values of $\beta$ were estimated for individual temperature response curves shown in Fig. 5. Values of $\beta$ and $P_{m 30}$ determined by least squares fit to the Niinemets-Reichstein model are also shown. In cases where temperature variation in the measured data was insufficient to determine a value of $\beta$, the mean value of 0.08 was used. Values of leaf mass per unit area (LMA, $\mathrm{g} \mathrm{m}^{-2}$ ) are provided for broad-leaved species and grasses to allow conversion to area-based units.

\begin{tabular}{llcccc}
\hline Species & Leaf Age & LMA & \multicolumn{2}{c}{ Value of $\beta$} & $P_{m 30}$ \\
\hline & (Node \#) & $\left(\mathrm{g} \mathrm{m}^{-2}\right)$ & Fig. 5 & Model & $\left(\mu \mathrm{g} \mathrm{g}^{-1} \mathrm{~h}^{-1}\right)$ \\
\hline Pinus taeda & Mature & - & 0.045 & 0.036 & 0.52 \\
P. taeda & Mature & - & - & $(0.08)$ & 0.7 \\
P. taeda & Nearly mature & - & - & 0.164 & 0.23 \\
P. taeda & Immature & - & 0.052 & 0.077 & 1.22 \\
P. taeda & Mature & - & - & - & 0.22 \\
Pinus sabiniana & Mature & - & 0.062 & 0.093 & 0.14 \\
P. sabiniana & Mature & - & 0.119 & 0.186 & 0.20 \\
Mangifera indica & Immature (1) & 58 & - & 0.076 & 6.3 \\
M. indica & Immature (11) & 63 & - & $(0.08)$ & 11.6 \\
Populus deltoides & Immature (5) & 51 & 0.076 & 0.118 & 4.14 \\
P. deltoides & Mature (10) & 82 & 0.055 & 0.111 & 1.71 \\
P. deltoides & Immature (4) & 45 & 0.094 & 0.096 & 13.3 \\
$P$. deltoides & Immature & 40 & - & 0.182 & 13.6 \\
P. deltoides & Mature & 86 & - & 0.195 & 1.42 \\
P. deltoides & Immature (6) & 33 & 0.090 & 0.084 & 21.4 \\
P. deltoides & Immature (4) & 30 & 0.063 & 0.074 & 25.5 \\
P. deltoides & Immature (2) & 65 & - & 0.055 & 12.8 \\
P. deltoides & Mature (9) & 56 & - & 0.164 & 3.2 \\
P. deltoides & Immature (4) & 45 & 0.089 & 0.088 & 12.2 \\
Sorghum bicolor & Mature & 27 & - & $(0.08)$ & 6.5 \\
S. bicolor & Less mature & 25 & - & $(0.08)$ & 4.5 \\
Festuca sp. & Mature & 52 & - & - & 1.7 \\
\hline & & & & &
\end{tabular}

assigned to $\beta$.

Although there is new and convincing evidence that diurnal variation in growth rate of expanding leaves leads to variations in rates of methanol production (Hüve et al., 2007), these effects are not yet sufficiently well characterized to incorporate into the model. Similarly, despite data raising the possibility of reduced rates of production at night (e.g., Fig. 14), we lack convincing evidence of a direct effect of varying PPFD on methanol production, and effects of varying light in the model are mediated via PPFD controls over $\mathrm{g}_{s}$. Although not currently included in the model, the potential effects of varying leaf expansion rates and/or direct effects of PPFD on methanol production rates should be kept in mind, as they may help explain some observed discrepancies between measurements and model predictions presented below.

For each of the data sets presented below, we applied model fits using the default parameterizations provided by Niinemets and Reichstein (2003a). The Solver function in Microsoft Excel was used to iterate for the best-fit values of $P_{m 30}$ and $\beta$ (Eq. 1), values of which are given in each figure caption and listed in Table 1. Our aim was to evaluate the suitability of the model for simulating methanol emissions for several species and over a wide range of light, temperature and measured stomatal conductance. Examining each data set in the context of the model also sheds light on the relative contributions of temperature and $\mathrm{g}_{s}$ in determining emissions, as well as the possibility of a direct influence of PPFD.

\section{Results}

Methanol emission measurements were made concurrently with measurements of net photosynthesis and transpiration for several tree species: loblolly pine (Pinus taeda), grey pine (P. sabiniana), cottonwood (Populus deltoides), mango (Mangifera indica) and two grasses, sorghum-sudangrass (Sorghum bicolor) and fescue (Festuca sp.). Measurements on a given leaf or set of needles were made over several hours, occasionally over several days, and in general, incident PPFD and leaf temperature were varied over a wide range. These measurements are summarized in Table 1.

Early in the course of these experiments, it became clear that short-term controls over methanol emissions were not straightforward. Incident PPFD and leaf temperature, which alone or in combination largely control short-term variation 


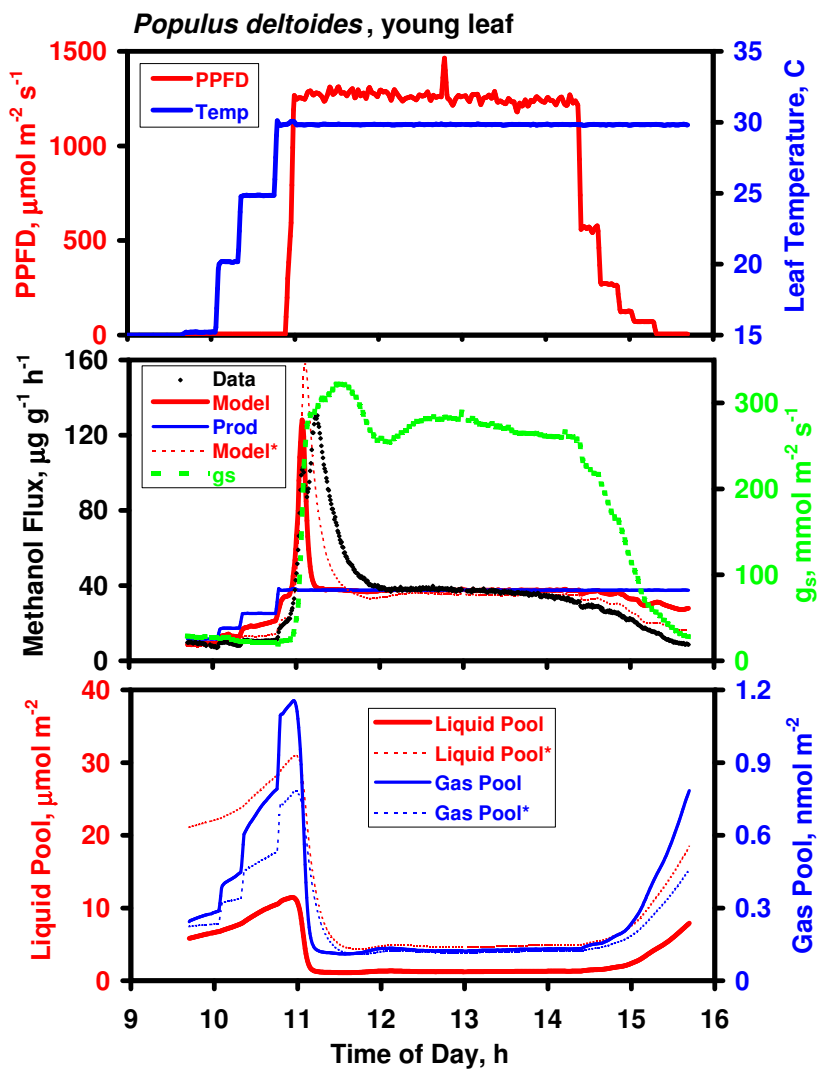

Fig. 1. Methanol emission data measured over a six-hour period on an immature leaf of Populus deltoides. Top panel: Incident PPFD and measured leaf temperature. Middle panel: Measured rates of methanol emissions and stomatal conductance, and rates of methanol production and methanol emissions predicted by the Niinemets-Reichstein model. Emissions predicted using the default broadleaf parameterization (in the absence of temperature variation in the light, $\beta$ was set to $0.08 ; P_{m 30}=38.1 \mu \mathrm{gg}^{-1} \mathrm{~h}^{-1}$ ) are shown in solid red line; those predicted assuming a pool of liquid water four times that of the default parameterization $(\beta=0.08$; $\left.P_{m 30}=35.7 \mu \mathrm{g} \mathrm{g}^{-1} \mathrm{~h}^{-1}\right)$ are shown in dashed red line. Bottom panel: Modeled aqueous and gas phase pools of methanol within the leaf for the default case (solid lines) and those predicted assuming four times the liquid water within the leaf (dashed lines). It has come to our attention that those suffering from various forms of color blindness may have difficulty interpreting this and other figures; we encourage them to contact the corresponding author for clarification.

of isoprene and monoterpene fluxes (Kesselmeier and Staudt, 1999), were inadequate to fully explain short-term or diurnal variations in the emissions of methanol. Although in certain situations methanol emission responded to variations in both PPFD and temperature, there was clearly another level of short-term control. Previous studies (MacDonald and Fall, 1993; Nemecek-Marshall et al., 1995) had clearly demonstrated that, under certain circumstances, stomata could strongly limit methanol emissions, and we examined whether such effects were evident in our data and, if

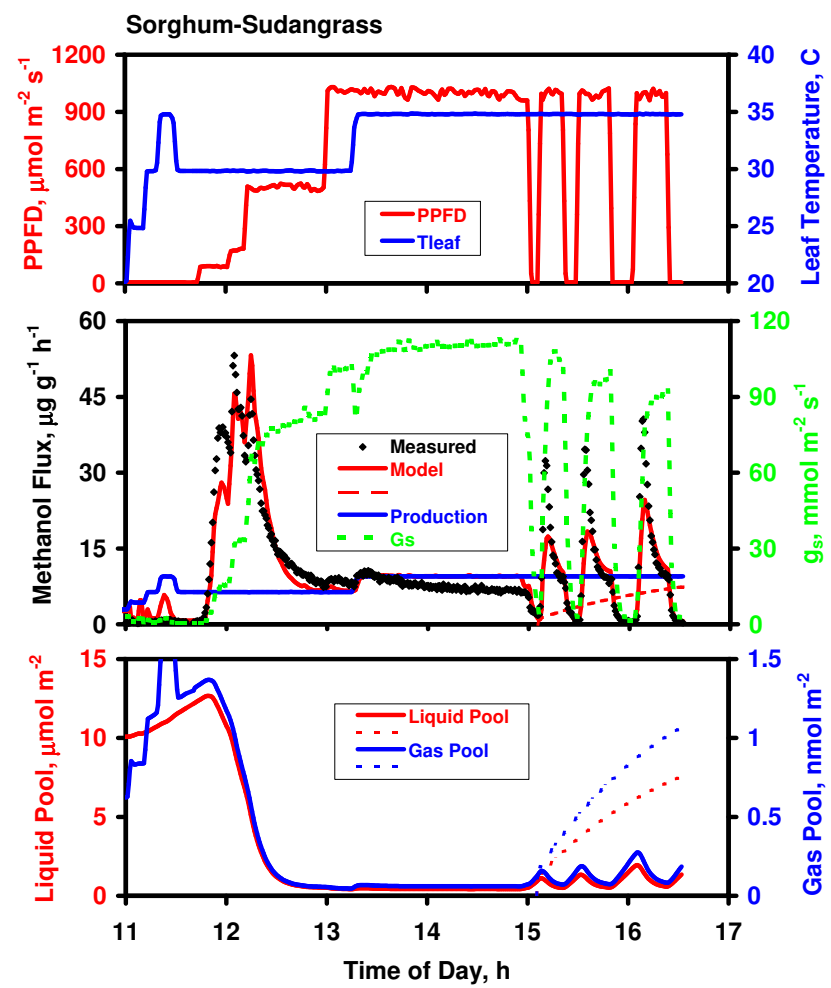

Fig. 2. Methanol emission data measured over five and a half hours on a leaf of Sorghum bicolor. Top panel: Incident PPFD and measured leaf temperature. Middle panel: Measured rates of methanol emissions and stomatal conductance, and rates of methanol production and methanol emissions predicted by the Niinemets-Reichstein model using the default parameterization for Phaseolus vulgaris (in the absence of significant temperature variation, $\beta$ was set to 0.08 ; $\left.P_{m 30}=6.5 \mu \mathrm{g} \mathrm{g}^{-1} \mathrm{~h}^{-1}\right)$. Dashed red line represents modeled emissions if stomata are assumed to remain closed following closure at 15:00 h. Bottom panel: Modeled aqueous and gas phase pools of methanol within the leaf (solid lines). Dashed lines represent modeled pool sizes if stomata are assumed to remain closed following 15:00 h.

so, the extent to which they obscured possible effects of light or temperature.

Figure 1 depicts methanol emission data from an expanding leaf of Populus deltoides, along with light and temperature data and measured stomatal conductance. Prior to 11:00, the leaf was in the dark, and both $\mathrm{g}_{s}$ and methanol emissions were low. At approx. 11:00, the light was turned on, resulting in rapid stomatal opening accompanied by an extremely large burst of methanol emission that reached a maximum rate exceeding $120 \mu \mathrm{g} \mathrm{g}^{-1} \mathrm{~h}^{-1}$ and persisted for about an hour. With light and leaf temperature then held constant, methanol emissions remained fairly stable at rates between 30 and $40 \mu \mathrm{gg}^{-1} \mathrm{~h}^{-1}$, presumably reflecting the steady-state rate of production. Following 14:30, PPFD was gradually reduced to zero, resulting in parallel declines in both methanol release and $\mathrm{g}_{s}$. 
Another case of stomatal control over emissions is illustrated in Fig. 2, depicting data from a leaf of Sorghum bicolor, the stomata of which respond very rapidly to changes in PPFD. In addition to the characteristic burst of emissions upon illumination in the morning, a series of light/dark/light transitions in the afternoon illustrate the extent to which methanol emissions can respond to changes in stomatal aperture. While leaf temperature was maintained constant at $35^{\circ} \mathrm{C}$, the light was turned off for periods of $6.5,8.1$ and $13.2 \mathrm{~min}$. Each time the light fell to zero, stomata responded rapidly, values of $\mathrm{g}_{s}$ dropping from $>100$ to $<5 \mathrm{mmol} \mathrm{m}^{-2} \mathrm{~s}^{-1}$ in less than $6 \mathrm{~min}$; methanol emissions dropped in parallel to near zero. Each time the light was turned on again, stomata began to re-open almost immediately, accompanied by a burst of methanol emission, which reached values significantly higher than the steady-state values prior to the onset of darkness. The magnitude of the burst generally increased as the amount of time spent in darkness increased.

Model fits to the data are included in Figs. 1 and 2 (red line; note that in the absence of significant temperature variation, we used a value of $\beta=0.08$ and iterated only for $P_{m 30}$ ). For the expanding leaf of cottonwood (Fig. 1), the model predicts the observed burst of methanol emission following stomatal opening in the morning, as well as the decline in emissions as PPFD was gradually reduced in the late afternoon. However, neither the magnitude and dynamics of the morning burst nor the rate of decline in the afternoon were well captured by the model. A model fit to the Sorghum data in Fig. 2 captures reasonably well both the early morning methanol burst and the afternoon dynamics of emissions during the sequence of light/dark/light transitions. However, the model underestimates the maximum rate of emissions observed during rapid stomatal reopening in the afternoon. Although both of these simulations fail to capture accurately the magnitude and precise dynamics of the observed emission bursts, in a qualitative sense, they describe the observed behavior quite well, confirming the potential short-term control by stomata of emissions of highly soluble VOC such as methanol.

Note that both the observed morning burst of methanol and the declines in methanol emission when the light was turned off and subsequent bursts of emission on re-illumination are generated in the model simply by the interaction of stomatal conductance and the partitioning of methanol between gas and liquid pools as determined by Henry's law constant. To illustrate the importance of pool dynamics, changes in the methanol pool sizes predicted by the model are shown in the bottom panels of Figs. 1 and 2. The bursts of emission in the morning result from the large buildup of leaf methanol pools overnight, followed by rapid increases in $\mathrm{g}_{s}$ upon illumination. The burst continues until pools are depleted. The magnitude of the early morning methanol burst is thus largely determined by overnight rates of production and $\mathrm{g}_{s}$, as well as by the overall size of the water pool into which methanol
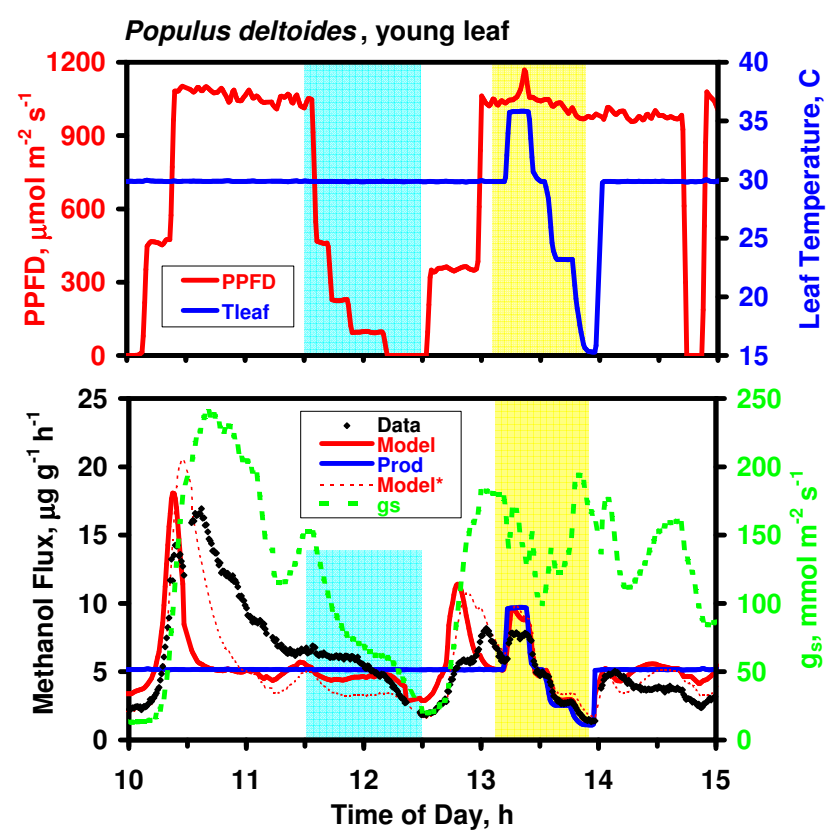

Fig. 3. Methanol emission data measured over five hours on an immature leaf of Populus deltoides. Top panel: Incident PPFD and measured leaf temperature. Bottom panel: Measured rates of methanol emissions and stomatal conductance, and rates of methanol production and methanol emissions predicted by the Niinemets-Reichstein model. Emissions predicted using the default parameterization $\left(\beta=0.106 ; P_{m 30}=5.24 \mu \mathrm{gg}^{-1} \mathrm{~h}^{-1}\right)$ are shown in solid red line; those predicted assuming a pool of liquid water four times that of the default parameterization $(\beta=0.155$; $P_{m 30}=4.80 \mu \mathrm{g} \mathrm{g}^{-1} \mathrm{~h}^{-1}$ ) are shown in dashed red line.

can partition. With rapid stomatal closure (Fig. 2) and the restriction of emissions, both liquid and gas phase pools immediately begin to increase. However, because methanol partitions overwhelmingly to the liquid phase, gas phase concentrations increase far too slowly in the short term to compensate for the decrease in stomatal conductance, with the result that methanol emissions decrease rapidly to near zero. Upon rapid stomatal re-opening, the elevated leaf pools are depleted in a short-term burst before emissions return to values near the steady-state rates prior to stomatal closure.

Note that although rapid stomatal closure, as in Fig. 2 at 15:00, causes a rapid decline in methanol emissions both in the data and the model, modeled emissions will not remain depressed indefinitely, assuming that production continues. Following the initial drop in $\mathrm{g}_{s}$, we held $\mathrm{g}_{s}$ constant in the model at the minimum measured value $\left(5 \mathrm{mmol} \mathrm{m}^{-2} \mathrm{~s}^{-1}\right)$ for the next hour and a half. Modeled pools of both liquid and gas phase methanol slowly increased (dashed lines in bottom panel), leading to a gradual recovery of modeled emissions towards pre-closure values. This underscores the fact, stressed by Niinemets and Reichstein (2003a), that stomata cannot limit emissions in the steady-state, but only during the 


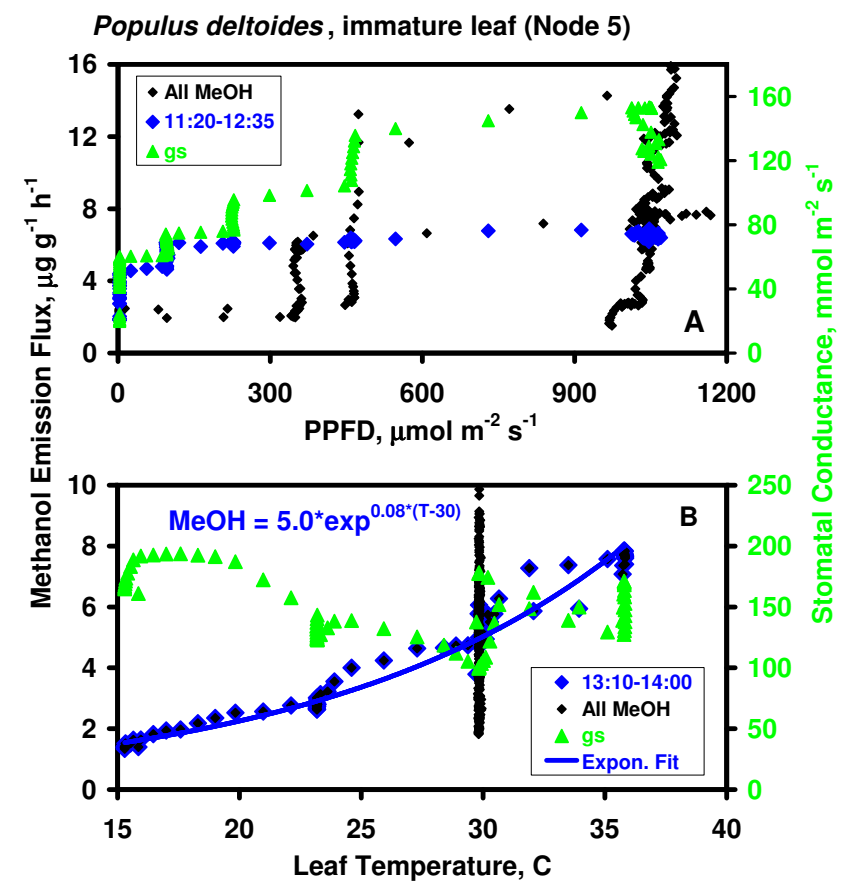

Fig. 4. Rates of methanol emission and stomatal conductance as a function of incident PPFD (top panel) and leaf temperature (bottom panel), re-plotted from the data in Fig. 3. Black symbols represent all methanol emission data in Fig. 3. Top panel: Blue and green symbols represent methanol and conductance data, respectively, collected between 11:20 and 12:35 (blue shaded area in Fig. 3) with leaf temperature constant at $30^{\circ} \mathrm{C}$. Bottom panel: Blue and green symbols represent methanol and conductance data collected between 13:10 and 14:00 (yellow shaded area in Fig. 3) with PPFD at approximately $1000 \mu \mathrm{mol} \mathrm{m}^{-2} \mathrm{~s}^{-1}$. An exponential fit to the blue symbols is shown.

transition to new steady-state values following a significant perturbation.

Having confirmed the observation that $\mathrm{g}_{s}$ can control methanol emissions under conditions of rapidly changing stomatal aperture, we sought to elucidate the potential importance of leaf temperature and PPFD in controlling emissions when stomata were in the steady state or $\mathrm{g}_{s}$ was changing only slowly. Figure 3, depicting $5 \mathrm{~h}$ of data collected from a young leaf of Populus deltoides, demonstrates a significant effect of environmental variables. Following the expected burst when the light was turned on in the morning, methanol emissions gradually decayed over the next hour, during which time PPFD and leaf temperature remained constant at approx. $1050 \mu \mathrm{mol} \mathrm{m}^{-2} \mathrm{~s}^{-1}$ and $30^{\circ} \mathrm{C}$. Due to the early morning burst/decay in emissions, which was largely independent of light and temperature, methanol emissions in the complete 5-h data set exhibit no unique relationship with either PPFD or temperature (Fig. 4). However, after the initial methanol burst subsided at approx. 11:20, emissions clearly responded to variations in both PPFD and leaf

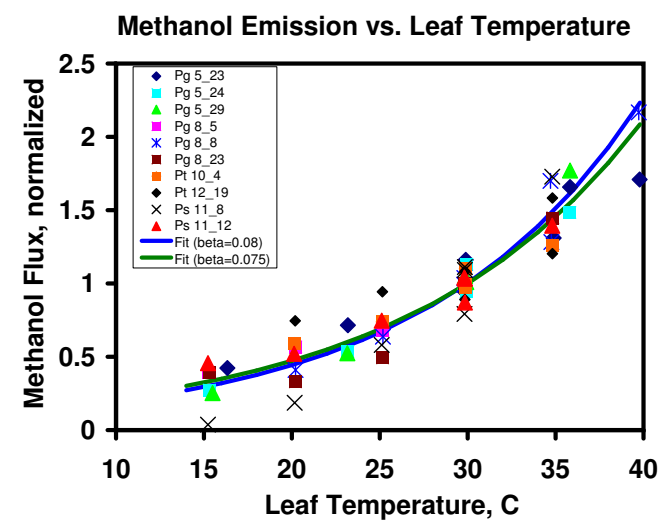

Fig. 5. MeOH emissions from ten leaves or sets of needles as a function of leaf temperature (Pd: Populus deltoides; Pt: Pinus taeda; Ps: $P$. sabiniana). Data from each data set were normalized to a value of 1.0 at $30^{\circ} \mathrm{C}$. Values of $\beta$ for each data set are shown in parentheses in legend. Exponential fits to entire data set $(\beta=0.082)$ and fit using mean value for all individual data sets $(\beta=0.075)$ are shown.

temperature. Methanol emissions as a function of PPFD are plotted in Fig. 4a; between 11:30 and 12:30 (blue shading in Fig. 3), during which time leaf temperature remained constant at $30^{\circ} \mathrm{C}$, both methanol emissions and $\mathrm{g}_{s}$ declined in response to decreasing PPFD, although the effect on emissions only became apparent at PPFD $<150 \mu \mathrm{mol} \mathrm{m}^{-2} \mathrm{~s}^{-1}$. Emissions versus leaf temperature data, including those collected between 13:10 and 14:00 (yellow shading in Fig. 3) when PPFD remained constant at approx. $1000 \mu \mathrm{mol} \mathrm{m}^{-2} \mathrm{~s}^{-1}$, are shown in Fig. 4b. Included is an exponential fit to the data collected during this period; each $10^{\circ} \mathrm{C}$ increase in temperature resulted in a 2.2 -fold increase in emissions (i.e., $Q_{10}=2.2$ ). The increase in methanol emissions as temperature increased is clearly not related to changes in $\mathrm{g}_{s}$, which decreased with increasing temperatures. The reduction in $\mathrm{g}_{s}$ as light was reduced, however, generally paralleled declines in methanol emissions. Thus, the degree to which declining methanol emissions were a direct response to decreasing light versus an indirect response to stomatal closure is ambiguous. The model fit to the data in Fig. 3 captures the salient features of the diurnal response but dramatically underestimates the duration of the early morning emission burst.

To further explore the relationship between methanol emissions and temperature, data similar to that in Fig. 4b, relating methanol emissions to leaf temperature at high PPFD $\left(>750 \mu \mathrm{mol} \mathrm{m}^{-2} \mathrm{~s}^{-1}\right)$, were obtained on 10 different leaves or sets of needles. All data were collected after 11:00, following any significant emission burst. This protocol can't preclude stomatal limitation of emissions, but minimizes the stomatal contribution. All data were normalized to give a value of 1.0 at $30^{\circ} \mathrm{C}$, and the results are plotted in Fig. 5. An exponential increase in methanol emissions with temperature appears to be a general response, with the relationship being 


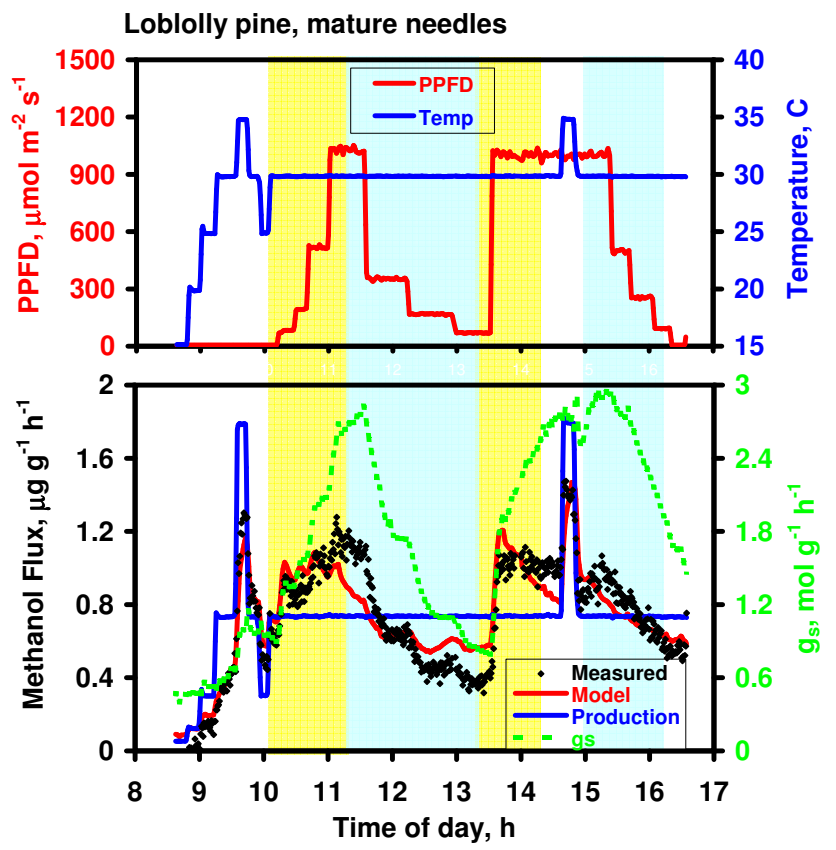

Fig. 6. Methanol emission data measured over eight hours on mature needles of Pinus taeda. Top panel: Incident PPFD and measured temperature. Bottom panel: Measured rates of methanol emissions and stomatal conductance, and rates of methanol production and methanol emissions predicted by the Niinemets-Reichstein model. Emissions predicted using the default parameterization $\left(\beta=0.18 ; P_{m 30}=0.22 \mu \mathrm{g} \mathrm{g}^{-1} \mathrm{~h}^{-1}\right)$ are shown in solid red line.

well described by,

$E_{m}($ normalized $)=\exp ^{(\beta *[\text { Tleaf-30] })}$

The value of $\beta$ that best fits the entire data set is 0.082 , similar to the value of 0.09 often used to describe the temperature response of monoterpene emissions (range 0.0570.144; Guenther et al., 1993) and corresponding to a $Q_{10}$ of 2.3. If each of the 10 data sets is fit independently to Eq. (2), the values of $\beta$ range from 0.045 to 0.119 (Mean $\pm \mathrm{sd}=0.075 \pm 0.023$ ), comparable to the range of estimates for monoterpene emissions.

The relationship between PPFD, $\mathrm{g}_{s}$ and methanol emissions is further examined in Fig. 6, using data obtained from mature needles of loblolly pine. Following light on at about 10:00, temperature was constant at $30^{\circ} \mathrm{C}$ for $6.5 \mathrm{~h}$ (except for a brief excursion at 14:45) and PPFD was varied. Both $\mathrm{g}_{s}$ and methanol flux generally tracked changes in PPFD, but again the extent to which stomata control the flux is unclear. If methanol emissions are plotted against both PPFD and $\mathrm{g}_{s}$, however, a clearer picture emerges (Fig. 7). The correlation between methanol flux and PPFD is apparent, but fairly weak. In contrast, the correlation with $\mathrm{g}_{s}$ is strong, although two distinct relationships appear, depending on whether $\mathrm{g}_{s}$ was increasing (yellow shading in Fig. 6) or decreasing (blue shading). Methanol is linearly related to $\mathrm{g}_{s}$ during periods
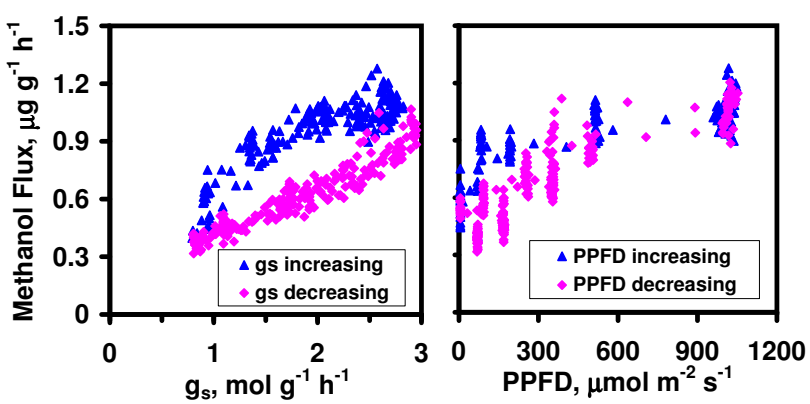

Fig. 7. Methanol emissions data from Fig. 6 re-plotted as a function of stomatal conductance (left panel) and incident PPFD (right panel). Only data collected at a leaf temperature of $30^{\circ} \mathrm{C}$ are plotted, and data are segregated according to whether PPFD and $\mathrm{g}_{s}$ were increasing (yellow shaded areas in Fig. 6) or decreasing (blue shaded areas in Fig. 6).

of both increasing and decreasing PPFD and $\mathrm{g}_{s}$. However, at a given value of $\mathrm{g}_{s}$, methanol emissions are higher when stomata are opening, consistent with the emptying of liquid phase methanol pools that accumulate during periods of low stomatal conductance.

When a model fit was applied, predictions tracked well with measured emissions and with $\mathrm{g}_{s}$, exceeding rates of production when stomata were opening and falling below rates of production when stomata were closing. During periods of decreasing $\mathrm{g}_{s}$, predicted emissions decreased linearly with conductance, but the fit to the data represented a compromise, overestimating in some regions and underestimating in others. Although emissions deviated in the short term from modeled production rates, the methanol produced in the model, integrated over the $7.5 \mathrm{~h}$ period $\left.\left(5.83 \mu \mathrm{g} \mathrm{g}^{-1}\right)\right)$, was very similar to the measured emissions $\left(5.75 \mu \mathrm{g} \mathrm{g}^{-1}\right)$, as must be the case, given that the potential storage pools within the leaf are small, relative to even these low rates of production.

Another example is provided by a young leaf of mango (Fig. 8). Note particularly the significant bursts of methanol emission (at 13:30 and 15:45, denoted by blue shading) which occurred upon re-illumination following a short period of darkness (15-25 $\mathrm{min}$ ) that caused stomata to close almost completely. If emissions between noon and 15:45, measured at constant temperature of $30^{\circ} \mathrm{C}$, are plotted against $\mathrm{g}_{s}$ (Fig. 9), a clear linear relationship emerges, suggesting that stomatal conductance plays a significant controlling role for much of the day, temperature remaining constant. Only those periods immediately after illumination following a period of darkness (shaded regions in Fig. 8; red and green asterisks in Fig. 9) exhibit a burst of emissions and deviate from the general relationship between $\mathrm{g}_{s}$ and methanol emissions.

Methanol emissions from the same leaf of mango on the previous day, with light held constant at approx. $1000 \mu \mathrm{mol} \mathrm{m}^{-2} \mathrm{~s}^{-1}$, failed to show an exponential 


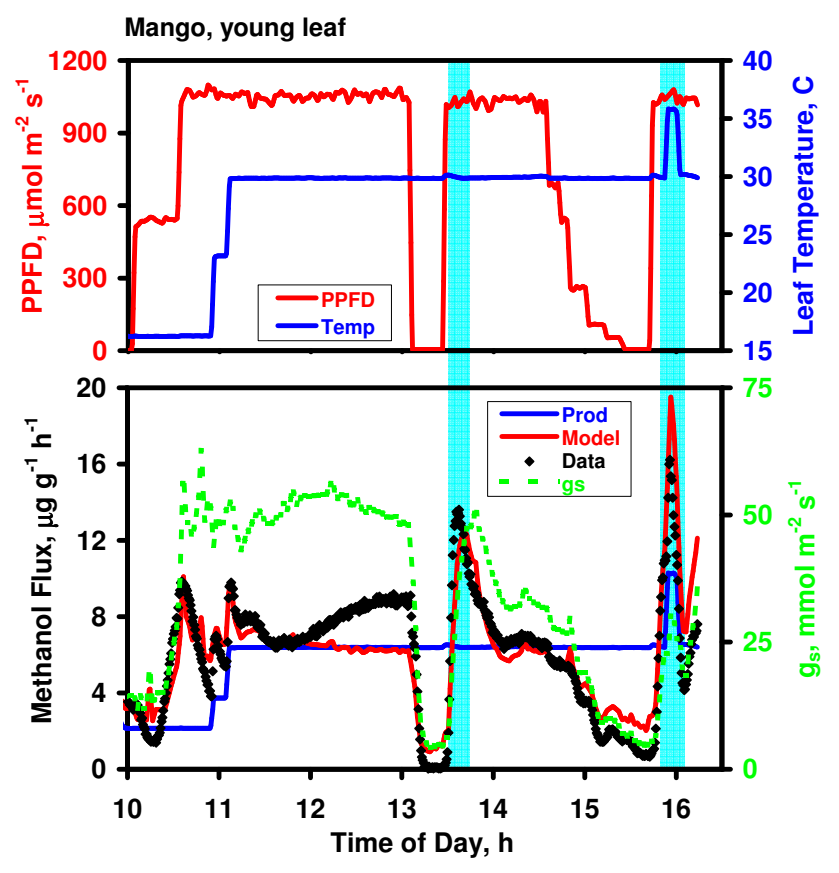

Fig. 8. Methanol emission data measured over six hours on an immature leaf of Mangifera indica. Top panel: Incident PPFD and measured leaf temperature. Bottom panel: Measured rates of methanol emissions and stomatal conductance, and rates of methanol production and methanol emissions predicted by the Niinemets-Reichstein model. Emissions predicted using the broadleaf tree default parameterization are shown in solid red line (in the absence of significant temperature variation $\beta$ was set equal to 0.08 and $P_{m 30}=6.46 \mu \mathrm{g} \mathrm{g}^{-1} \mathrm{~h}^{-1}$ ).

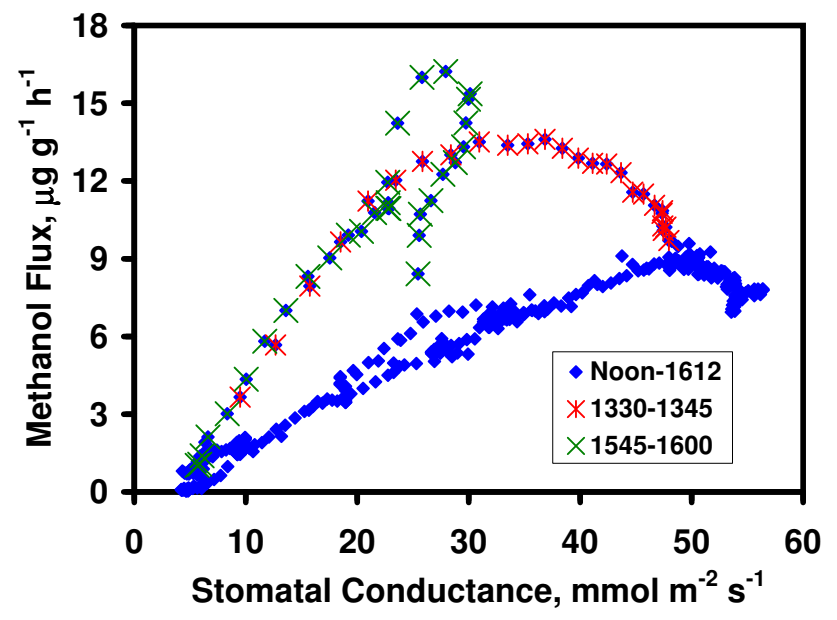

Fig. 9. Methanol emission fluxes from the mango leaf in Fig. 8 plotted as a function of stomatal conductance. Superimposed on all data collected from noon to 16:12 (blue symbols) are data from periods characterized by stomatal opening immediately following periods of darkness and stomatal closure (asterisks), denoted by blue shading in Fig. 8.

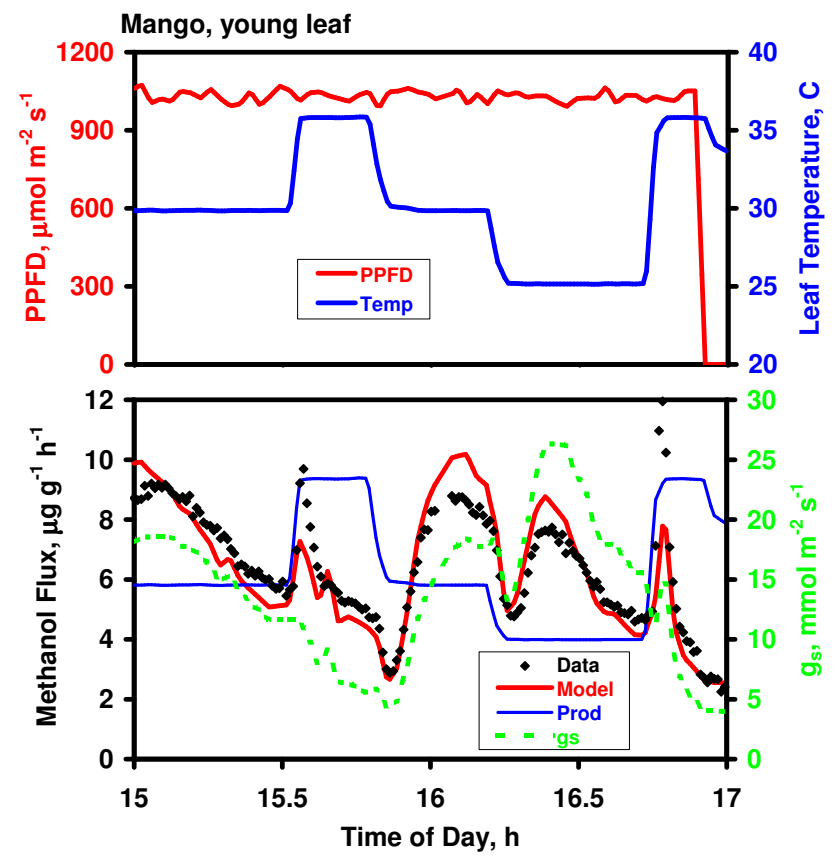

Fig. 10. Methanol emission data measured over two hours on an immature leaf of Mangifera indica (same leaf as Figs. 8 and 9). Top panel: Incident PPFD and measured leaf temperature. Bottom panel: Measured rates of methanol emissions and stomatal conductance, and rates of methanol production and methanol emissions predicted by the Niinemets-Reichstein model. Emissions predicted using the broadleaf tree default parameterization are shown in solid red line (in the absence of significant temperature variation $\beta$ was set equal to 0.08 and $P_{m 30}=6.46 \mu \mathrm{g} \mathrm{g}^{-1} \mathrm{~h}^{-1}$ ).

increase with temperature (Fig. 10), contrasting with the situation observed in cottonwood (Fig. 3). Emissions fluctuated wildly, and bore a closer relationship to stomatal conductance than to temperature. This is confirmed when emissions are plotted versus $\mathrm{g}_{s}$ (Fig. 11a) and, at a given temperature, increased linearly with $\mathrm{g}_{s}$. The slope of the response increased with temperature however, and if the emissions predicted by the three lines are compared at a common stomatal conductance value of $15 \mathrm{mmol} \mathrm{m}^{-2} \mathrm{~s}^{-1}$, the $Q_{10}$ is 2.4 , similar to the value obtained in a different fashion in Fig. 4b. Interestingly, if emissions are plotted against leaf transpiration rate (Fig. 11b), the three curves collapse on each other.

Model fits to the data in Figs. 8 and 10 capture much of the observed variation in emissions. In Fig. 8, the model describes qualitatively the bursts in emission when stomata re-open following a period of darkness, and mimics the control of emissions by $\mathrm{g}_{s}$ in the afternoon, although significantly underestimating measured rates between 11:00 and 13:00. As with the loblolly data above (Fig. 6) the modeled methanol emission rates tended to exceed rates of production during and after rapid stomatal opening and fell below production rates when stomata were closing, indicating significant stomatal control of emissions during those periods. 

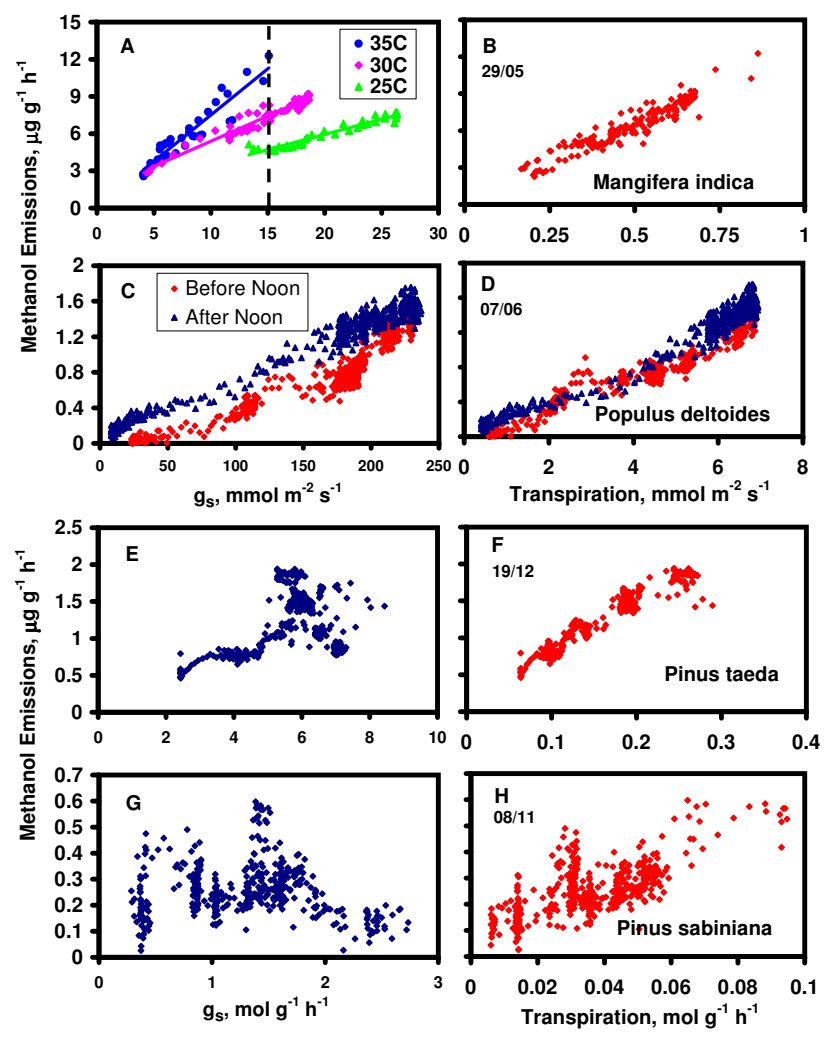

Fig. 11. Measured rates of methanol emission as a function of stomatal conductance (left panels) and as a function of transpiration (right panels) for leaves of four different species, mango (A, B), cottonwood (C, D), loblolly pine $(\mathbf{E}, \mathbf{F})$ and gray pine $(\mathbf{G}, \mathbf{H})$. Rates of stomatal conductance and transpiration are expressed on a leaf area basis for the two broadleaved species and on a dry mass basis for the two pines.

In Fig. 10, in which emissions bear no obvious relationship with temperature or modeled rates of production, and appear to be controlled largely by variations in $\mathrm{g}_{s}$, they are well captured by the model. Despite the apparent control by $\mathrm{g}_{s}$, the effects of temperature on the slope of the emissions vs. $\mathrm{g}_{s}$ relationship (Fig. 11a) and the strong correlation between emissions and transpiration (Fig. 11b) clearly indicate that leaf temperature also plays a role. Indeed, if leaf temperature is held constant at $25^{\circ} \mathrm{C}$ in Fig. 10, attempts to model the observations are unsuccessful (not shown); only by combining temperature effects on production and the value of $H$ with variation in $\mathrm{g}_{s}$ is a successful simulation obtained.

Figure 12 depicts data obtained from two species of pine, with data from immature needles of loblolly pine in the left panel and similar data from mature needles of gray pine in the right panel. In both examples, emissions appeared to track closely with step changes in temperature and the model captures observed variations quite well. In neither case is a clear relationship with $\mathrm{g}_{s}$ apparent; indeed, if emissions are plotted versus $\mathrm{g}_{s}$ (Fig. 11e, g), the relationship between the
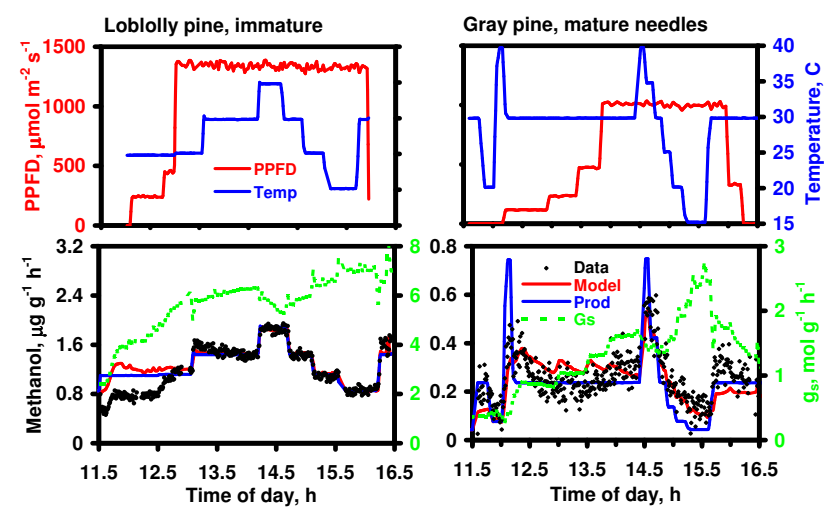

Fig. 12. Methanol emission data measured over five hours on immature needles of loblolly pine (left panels) and mature needles of gray pine (right panels). Top panels: Incident PPFD and measured leaf temperature. Bottom panels: Measured rates of methanol emissions and stomatal conductance, and rates of methanol production and methanol emissions predicted by the Niinemets-Reichstein model. Emissions predicted using the default parameterization for pine are shown in solid red lines (loblolly: $\beta=0.054$ and $P_{m 30}=1.45 \mu \mathrm{g} \mathrm{g}^{-1} \mathrm{~h}^{-1}$; gray: $\beta=0.116$ and $\left.P_{m 30}=0.24 \mu \mathrm{gg}^{-1} \mathrm{~h}^{-1}\right)$.

two is quite weak. Of particular interest in both panels is the interval between approximately 14:30 and 16:00 when measured methanol emissions and stomatal conductance strongly diverged, and emissions are explained largely by direct effects of temperature on methanol production and, to a lesser extent, the value of $H$. Niinemets and Reichstien (2003a) previously demonstrated that temperature dependent changes in the value of $H$ influenced modeled emissions, independent of any changes in methanol production. As seen above, if emissions are plotted against leaf transpiration rate (Fig. 11f, h), effects of varying temperature are incorporated and the correlations become much stronger.

\subsection{Methanol emissions at night}

The fact that PPFD and $\mathrm{g}_{s}$ are strongly correlated makes it difficult to distinguish between direct effects of light on methanol production and indirect effects on emission via changes in stomatal aperture. During brief periods of darkness (e.g., Figs. 2, 8), emissions sometimes fell to near zero, but in each case, the decline in emissions was accompanied by very rapid and nearly complete stomatal closure. In other cases, early morning rates of emission in plants kept in the dark overnight (e.g., Fig. 13) were quite low but significantly above zero. We collected little data over extended periods of darkness, and the magnitude of methanol emissions at night remains a largely unexamined issue. In two cases, however, we measured methanol emissions from leaves of cottonwood continuously from late afternoon until noon the following day (Fig. 14). In both the mature (left panel) and rapidly 
growing leaves (right panel), emissions continued through the night, but at quite low rates, and clearly responded to gradual increases in $\mathrm{g}_{s}$ that occurred after midnight. When the light was turned on at the end of the dark period, stomata opened rapidly with simultaneous increases in emissions. Several hours after illumination, and long after any methanol burst should have subsided, emissions from the mature leaf (left panel) remained over three times higher than observed in the dark, temperature remaining constant at $20^{\circ} \mathrm{C}$. Similarly, in the young leaf, emissions at $30^{\circ} \mathrm{C}$ when the experiment was terminated at noon were over five times higher than emissions just prior to illumination (at $20^{\circ} \mathrm{C}$ ), an increase inconsistent with the average $Q_{10}$ value of 2.3 (Fig. 5).

\section{Discussion}

Ultimately, our goal is to develop a model of methanol emissions from forests and other ecosystems suitable for inclusion in regional and global scale atmospheric chemistry models. The leaf-level methanol emission measurements reported here were undertaken to elucidate short-term controls over emissions with the aim of incorporating such information into a leaf-level model. Our data clearly indicate that, in the short term (minutes to hours), daytime emissions of methanol are under joint control of leaf temperature and stomatal conductance.

4.1 Methanol response to rapid changes in stomatal conductance

Consistent with previous reports (Nemecek-Marshall et al., 1995; Hüve et al., 2007), we observed large bursts of methanol emissions when light was turned on after a prolonged period of darkness. These bursts were particularly dramatic in leaves with relatively high rates of emission (Figs. 1-3). Morning bursts of emission were less pronounced or undetectable in pine trees with low steady-state rates of emission (Fig. 12). Bursts of methanol emission, smaller and of shorter duration, were also observed following short-term (5 to $20 \mathrm{~min}$ ) periods of darkness, as long as stomata responded rapidly and methanol emissions were strongly limited during the dark period (Figs. 2 and 8).

Such behavior was qualitatively captured by the Niinemets-Reichstein model, and is explained by the short-term dynamics of the leaf methanol pool (Figs. 1 and 2). Pools that accumulate during extended periods of stomatal closure empty rapidly upon stomatal opening. Following rapid stomatal closure, newly produced methanol partitions strongly to the liquid phase, and a large increase in the liquid pool (and considerable time) is required before gas phase concentrations reach sufficiently high levels to counter the effects of decreased $\mathrm{g}_{s}$.

\subsection{Methanol response to varying light and temperature}

During periods not characterized by bursts of emission, and at constant leaf temperature, many of our data sets exhibit a striking linear relationship between emissions and $\mathrm{g}_{s}$ (Figs. 7, 9 and 11a, c), strong evidence of stomatal control. However, it is also apparent that leaf temperature operates simultaneously to control emissions. Thus, in Fig. 12, emissions in both loblolly and gray pine decreased during the afternoon as temperature was lowered stepwise, despite increasing $\mathrm{g}_{s}$. And although emissions in a young leaf of mango (Fig. 10) clearly fluctuated in concert with $\mathrm{g}_{s}$, a closer examination reveals three independent linear relationships between emissions and $\mathrm{g}_{s}$, the slopes of which are determined by leaf temperature (Fig. 11a).

When leaf temperature was varied while holding PPFD constant, a clear exponential relationship was revealed between methanol emissions and temperature (Figs. 4b, 5). We assumed that this reflected the temperature dependency of methanol production, and incorporated such a dependency in the model (Eq. 1). Although the data in Fig. 5 were obtained following any morning burst of emissions and with constant PPFD, $\mathrm{g}_{s}$ is dependent on leaf temperature and we cannot dismiss the possibility that stomatal changes affect emissions independently of temperature. Since $\mathrm{g}_{s}$ generally decreases as leaf temperature increases (e.g., Figs. 3, 12), stomatal limitations would tend to depress emissions with increasing temperature, in which case values of $\beta$ describing methanol production should be somewhat higher than those describing emission in Fig. 5. In addition, temperature dependent variations in $H$, affecting methanol solubility, are not taken into account.

In principle, the Niinemets-Reichstein model incorporates both stomatal effects and variations in $H$, and values of $\beta$ and $P_{m 30}$ obtained using non-linear least-squares regression techniques applied to each individual data set should better reflect the temperature dependency of methanol production. In Table 1, values of $\beta$ obtained for each curve in Fig. 5 (i.e., describing emissions) are compared with $\beta$ values obtained by inverting the Niinemets-Reichstein model (i.e., describing production). For those 10 data sets in which comparisons between the two methods could be made, agreement is reasonably good $\left(r^{2}=0.53\right)$, but on average estimates of $\beta$ derived from model fits were $21 \%$ greater than those obtained using emission data as a function of temperature.

Estimates of $\beta$ using least-squares analysis will only be valid if the model realistically captures the effects of varying stomatal conductance and light, or effects of variable rates of leaf expansion in growing leaves. If such behavior is not captured by the model, the value of $\beta$ will be adjusted to provide the best overall fit to the data, but may not accurately reflect the temperature dependency of methanol production. Consider the data in Fig. 3. Fitting the emissions data collected between 13:10 and 14:00 to leaf temperature (Fig. 4b) resulted in a $\beta$ value of 0.080 , compared to a value of 0.118 
when the entire data set was used to fit the model. The higher value of $\beta$ in the latter case results in large part from the inability of the model to capture the duration of the emission burst in the early morning; in a compromise, the fitting routine increases the steepness of the temperature response to provide the best fit to the entire data set, even though emissions are overestimated for much of the afternoon.

Plotting emissions versus transpiration often revealed a strong linear relationship (Fig. 11b, d, f, h). While this correlation might indicate that at least a portion of the methanol emitted by leaves is transported in the transpiration stream, we have no evidence for such a process. Transpiration simultaneously incorporates effects of both stomatal conductance and leaf temperature, since saturation vapor pressure, and therefore the water vapor concentration gradient, is strongly temperature dependent. The change in saturation vapor pressure with temperature can be closely approximated using an exponential function analogous to Eq. (1), with $\beta$ equal to 0.059 and $Q_{10}$ equal to 1.8 . Thus, a fortuitous correlation between transpiration and methanol emission arises, since both are proportional to $\mathrm{g}_{s}$ at constant temperature, and the average postulated $Q_{10}$ of methanol production is 2.3.

Although the model simulations presented above appear to capture the dominant short-term controls over methanol emissions, accounting for both the effects of leaf temperature (on methanol production and the value of $H$ ) and stomatal conductance, the model frequently underestimates the magnitude and duration of the methanol burst following stomatal opening in the morning. For instance, the model fit to Populus data in Fig. 1 generated a morning burst of emissions and also responded to stomatal closure as light was reduced in the afternoon, but in neither case was the magnitude or duration of the response well simulated. In the context of the Niinemets-Reichstein model, liquid and gas phase pools re-equilibrate far too rapidly following a perturbation. In the morning, the pools dropped precipitously at 11:00, forcing modeled emissions to decrease and equal the rate of production by 11:15. The measured burst, however, lasted until about noon, resulting in a significant model underestimate of emissions over this period. Similarly, in the late afternoon, when stomata closed in response to a gradual reduction in PPFD, the model responded only slightly while measured emissions fell by $75 \%$. This too is explained, in the context of the model, by an overly rapid re-equilibration of methanol pools, this time resulting in a rapid increase in the gas pool that counteracts the decrease in conductance, leading to a model overestimate of emissions during this period.

Any change to the model that retards the rate at which the liquid pool comes into equilibrium improves the model fit to the data, in both early morning and late afternoon. However, none of these modifications can be justified as realistic. For instance, if we increase by a factor of four the pool of liquid water into which methanol can partition, the time necessary for the liquid pool to equilibrate is extended. The resulting changes in pool dynamics and improvement in sim-

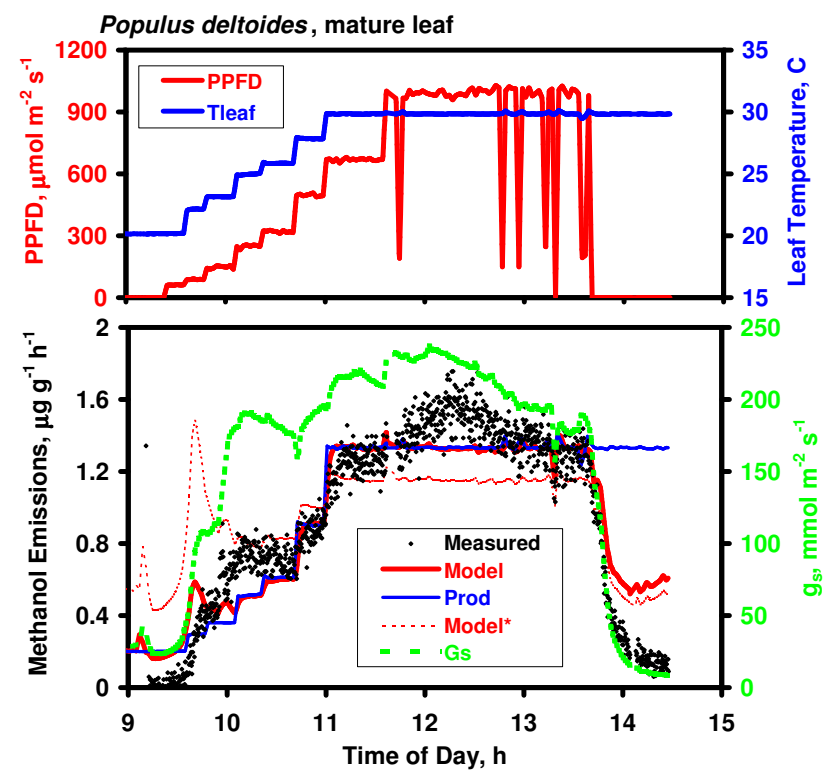

Fig. 13. Methanol emission data measured over five hours on a mature leaf of Populus deltoides. Top panel: Incident PPFD and measured leaf temperature. Bottom panel: Measured rates of methanol emissions and stomatal conductance, and rates of methanol production and methanol emissions predicted by the Niinemets-Reichstein model. Emissions predicted using the default parameterization $\left(\beta=0.195 ; P_{m 30}=1.02 \mu \mathrm{gg}^{-1} \mathrm{~h}^{-1}\right)$ are shown in solid red line; those predicted assuming a mean value of $\beta=0.08$ $\left(P_{m 30}=1.17 \mu \mathrm{g} \mathrm{g}^{-1} \mathrm{~h}^{-1}\right)$ are shown in dashed red line.

ulated emissions are illustrated in Fig. 1 by the dashed lines. Unfortunately, such an enhancement of the liquid water pool would imply over $2 \mathrm{~m}^{3}$ water per $\mathrm{m}^{3}$ leaf, a physical impossibility. Very similar improvements to the overall model fit (not shown) result from reducing the value of $H$ by a factor of 4 , to $0.115 \mathrm{~Pa} \mathrm{~m}^{3} \mathrm{~mol}^{-1}$, or by arbitrarily reducing $\mathrm{g}_{s}$ by a factor of 3 . Each of these changes also serves to slow the equilibration of the leaf methanol pools, improving the model fit during the early morning burst and the afternoon decline in emissions, yet neither can be justified.

Figure 3, illustrating emission data for another young cottonwood leaf, exhibits similar discrepancies between measurements and model predictions. Using the default parameterization, the morning burst in emissions is dramatically underestimated. Once again, arbitrarily increasing the pool of liquid water by a factor of four (dotted line) improves the situation, both during the morning burst and in the afternoon, although morning emissions remain substantially underestimated.

Although there is clear evidence that growth rates in expanding leaves vary substantially over the diurnal cycle, leading to corresponding variations in methanol release (Hüve et al., 2007), such effects are not well characterized and are not incorporated into the model. If rapid leaf growth in expanding leaves of Populus leads to enhanced methanol production 


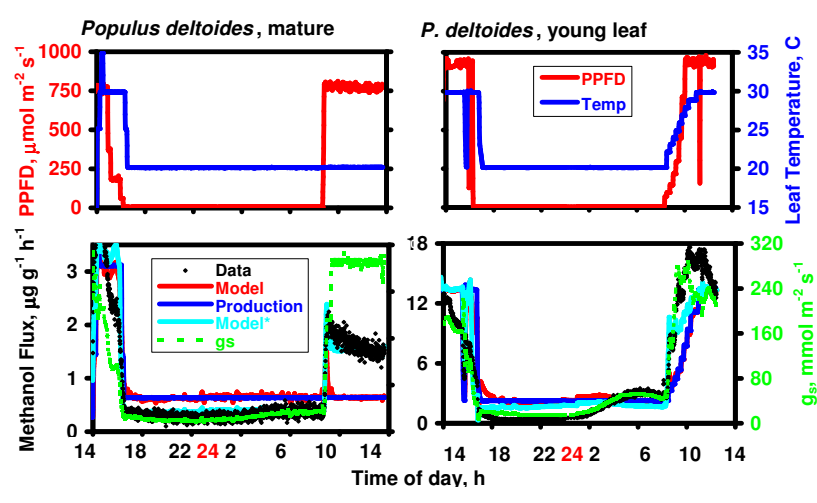

Fig. 14. Methanol emission data measured over $24 \mathrm{~h}$ on two leaves of Populus deltoides, one mature (left panels) and one immature (right panels). Top panels: Incident PPFD and measured leaf temperature. Bottom panels: Measured rates of methanol emissions and stomatal conductance, and rates of methanol production and methanol emissions predicted by the Niinemets-Reichstein model. Emissions predicted using the default pine parameterization are shown in red lines (left panel: $\beta=0.164 ; P_{m 30}=3.20 \mu \mathrm{gg}^{-1} \mathrm{~h}^{-1}$; right panel: $\beta=0.184 ; P_{m 30}=13.82 \mu \mathrm{gg}^{-1} \mathrm{~h}^{-1}$. Model predictions assuming a $75 \%$ reduction in $P_{m 30}$ in the dark are shown in light blue lines (left panel: $\beta=0.083 ; P_{m 30}=3.48 \mu \mathrm{gg}^{-1} \mathrm{~h}^{-1}$; right panel: $\beta=0.069 ; P_{m 30}=13.63 \mu \mathrm{gg}^{-1} \mathrm{~h}^{-1}$.

during early morning hours, it could explain the unusually large bursts of emission seen in Figs. 1 and 3.

\subsection{Possible effects of PPFD on methanol emissions}

Figure 13 presents two model fits to the data from a mature cottonwood leaf. When the entire data set was used to determine best fit values of $\beta$ and $P_{m 30}$, emissions tracked methanol production until stomata closed in the afternoon, and model predictions were good, although the model underestimated emissions at midday and overestimated emissions after the light was turned off and $\mathrm{g}_{s}$ reached low values in the afternoon. In order to obtain this fit, $\beta$ was assigned a value of $0.195\left(Q_{10}=7.0\right)$, well outside the range of those determined using the data in Fig. 5. If $\beta$ was assigned the mean value of 0.08 (dotted line), the overall fit suffered. Production and emissions at $20^{\circ} \mathrm{C}$ were seriously overestimated, and those at $30^{\circ} \mathrm{C}$ underestimated in order to compensate. In addition, a burst of emissions upon stomatal opening was predicted by the model but did not appear in the measured data. These model shortcomings could be an indication that the assumption of constant $P_{m 30}$ was invalid, and that $P_{m 30}$ increased through the morning hours. In an immature leaf, this might be a reflection of diurnal variation in leaf growth rate, as above, but such an explanation seems unlikely for this mature leaf. The very low emissions before the light was turned on in the morning and again after the light was turned off in the afternoon raise the possibility that production rates were reduced at low light or in the dark. Lower production rates in the dark and early morning would also reduce the morning burst of emissions.

Attempts to model the two overnight data sets in Fig. 14 were generally unsuccessful. In both cases, the predictions of nighttime emissions were inconsistent with daytime values, assuming that production was a function solely of leaf temperature. In both instances, if the entire data set was used to obtain production parameters, the fitting routine attempted to force a fit to the data by selecting values of $\beta$ significantly higher than the value of 0.082 used to fit the data in Fig. 5 (0.164 and 0.184 for left and right panels, respectively, in Fig. 14). Despite these unrealistically high $\beta$ values, the model in both cases overestimated nighttime emissions and underestimated those during the ensuing morning period. If we arbitrarily assume that methanol production is reduced by $75 \%$ in the dark, based on the difference in the left panel between emissions at $20^{\circ} \mathrm{C}$ in the dark (at 08:00) and in the light (at noon), new fits to both data sets are illustrated in the figure as dashed lines. Best-fit values of $\beta$ under this assumption were 0.083 and 0.069 for left and right panels, respectively. Although the overall fit is greatly improved, and the values of $\beta$ more consistent with data in Fig. 5, we hasten to point out that we have no independent evidence that production is reduced in darkness or during the night.

Niinemets and Reichstien (2002, 2003a) argued persuasively that a dynamic model incorporating effects of stomatal conductance is necessary for modeling the short-term emission dynamics of soluble VOC $\left(H<10 \mathrm{~Pa} \mathrm{~m}^{3} \mathrm{~mol}^{-1}\right)$ such as methanol, and this contention is strongly supported by our results. The large aqueous phase pool of methanol and the lag time necessary for its re-equilibration frequently uncouple the rate of emission from the instantaneous rate of production. A model based on the assumption that these pools are always in the steady-state, and that emissions are equal to rates of production will fail to capture many of those effects illustrated in our data. Which type of model is appropriate, however, depends on the purpose of the modeling exercise. If one is interested in understanding the short-term dynamics of methanol emissions, the Niinemets-Reichstein approach is clearly necessary, and captures the salient features of the observations. If the model goal is to predict emissions over the course of a day, short-term dynamics may be irrelevant, and a steady-state model may be suitable. However, to achieve reasonable predictions, a better understanding of variations in rates of methanol production is required.

To be of practical use, any model requires a methanol production term, such as $P_{m 30}$. No existing model is capable of accurately describing how $P_{m 30}$ varies between species, between leaves of the same species (within a plant canopy for instance), or over time in a given leaf. The relatively small amount of existing empirical data (MacDonald and Fall, 1993) suggest values from mature leaves of broadleaf trees (measured at $30^{\circ} \mathrm{C}$ ) ranging from 1.5 to $15 \mu \mathrm{g} \mathrm{g}^{-1} \mathrm{~h}^{-1}$, and a single measurement on conifer needles (Abies concolor) yielded emissions of $1.6 \mu \mathrm{g} \mathrm{g}^{-1} \mathrm{~h}^{-1}$. Highest rates (2.2 to 
$46 \mu \mathrm{g} \mathrm{g}^{-1} \mathrm{~h}^{-1}$ ) were obtained from a variety of crop species. Their measurements on "mature" leaves were performed on the youngest fully expanded leaf. Data from leaves of Populus deltoides (Nemecek-Marshall et al., 1995) suggest that methanol emissions drop from values of $10-15 \mu \mathrm{g} \mathrm{g}^{-1} \mathrm{~h}^{-1}$ on the youngest fully expanded leaf to values as low as 1$2 \mu \mathrm{g} \mathrm{g}^{-1} \mathrm{~h}^{-1}$ as leaves continue to mature. And in soybean, the first fully expanded leaf had emission rates approximately four times higher than older leaves lower on the stem. Thus, data obtained on the youngest fully expanded leaf is likely to overestimate emissions of more mature leaves. Holzinger et al. (2000) measured methanol emissions from branches of six plants of Quercus ilex at constant light and temperature $\left(25^{\circ} \mathrm{C}\right)$ and emissions ranged from 0.5 to 4.5 (mean=1.6) $\mu \mathrm{gg}^{-1} \mathrm{~h}^{-1}$. Our estimates of methanol emissions from a variety of species (Table 1), obtained in the afternoon, following any observed morning burst of emission, and during periods when stomatal conductance had been more or less constant for an hour or more, are considerably lower than the values reported by MacDonald and Fall. Steady-state values of mature leaves of trees, measured at $30^{\circ} \mathrm{C}$, ranged from 0.2 to $3.2 \mu \mathrm{g} \mathrm{g}^{-1} \mathrm{~h}^{-1}$, while higher values, ranging up to $38 \mu \mathrm{g} \mathrm{g}^{-1} \mathrm{~h}^{-1}$, were observed from expanding leaves of Populus. Conifers generally exhibited the lowest emission capacities, between 0.2 and $1.2 \mu \mathrm{g} \mathrm{g}^{-1} \mathrm{~h}^{-1}$. The single measurement on leaves of Festuca indicated emissions similar to those of broadleaf trees, but the few measurements made on apparently mature leaves of Sudangrass indicated relatively high rates of methanol production $\left(4.5-6 \mu \mathrm{g} \mathrm{g}^{-1} \mathrm{~h}^{-1}\right)$, somewhat at odds with the observation that grasses contain lower amounts of pectin in their cell walls (Galbally and Kirstine, 2002). More measurements are needed to constrain estimates of methanol production in mature leaves, but existing data suggest a relatively narrow range of perhaps 0.1 to $\left.4 \mu \mathrm{g} \mathrm{g}^{-1} \mathrm{~h}^{-1}\right)$.

It is an implicit assumption in the modeling exercises above that $P_{m 30}$ is constant throughout the day. However, leaf growth rates vary during the diurnal cycle, with different species exhibiting growth maxima around dawn, dusk or at midday (Walter and Schurr, 2005). The data of Hüve et al. (2007) indicate that the relationship between leaf growth rate and methanol production is complex. While a clear correlation between leaf growth and integrated methanol emission on a daily basis was evidenced, short-term emission dynamics were influenced both by rates of leaf growth, presumably influencing methanol production, and by variations in stomatal conductance. Furthermore, although emissions integrated over $24 \mathrm{~h}$ correlated well with growth over the same period, the times of maximum growth did not necessarily correspond to the times of maximum emission. Nevertheless, it is clear that the assumption of constant $P_{m 30}$ is unlikely to be valid, particularly for expanding leaves, and may account for some of the observed discrepancies between our measurements and model simulations. For the only two datasets that address the question of nighttime emissions (Fig. 14), the
Niinemets-Reichstein model is incapable of simulating both daytime and nighttime emissions unless methanol production is significantly restricted at night. Whether this is related to diurnal variation in growth rates or rates of leaf repair, or whether it is a direct effect of reduced light on production is unclear.

Galbally and Kirstine (2002) attempted to estimate global methanol emissions from flowering plants based on the assumption that all such methanol derived from the demethylation of cell wall pectin. They further assumed that the amount of pectin demethylated is related to net primary production. After making a number of additional assumptions relating to the amount of pectin in cell walls and the amount demethylated during growth, they were able to estimate, using their model, the ratio of carbon emitted as methanol to carbon taken up through photosynthesis. Their mean estimate of the ratio of methanol emissions to net primary production was $0.11 \%$ for tree and crop species, and $0.024 \%$ for grasses. These compared quite well to the few published values based on enclosure measurements or above canopy fluxes, which ranged from 0.02 to $0.24 \%$ for trees and crops and from 0.012 to $0.04 \%$ for grasslands. In our data, the instantaneous molar ratio of methanol emitted to rates of net photosynthesis varies widely, peaking during morning bursts of methanol when net photosynthesis was quite low, and reaching a minimum when leaf temperature was between 20 and $25^{\circ} \mathrm{C}$ and photosynthesis rates were maximal. Integrating over the entire measurement period, however, for each of the time course data sets presented above (excluding Fig. 14), our estimates ranged from $0.007 \%$ to $0.154 \%$. Minimum ratios, as expected, were associated with mature leaves of the pines and cottonwood, and maxima with young leaves of mango and cottonwood. The data obtained from sorghum $(0.022 \%)$ was on the low end of the range, comparing favorably with that of Galbally and Kirstine (2002).

Several low molecular weight oxygenated VOC, including formaldehyde, acetaldehyde, and various organic acids exhibit bi-directional fluxes, defined by a compensation point (Kesselmeier, 2001). By definition, when ambient concentrations exceed the compensation point, leaf uptake occurs, and vice versa. This is simply a reflection of the fact that the flux obeys Fick's law, and is proportional to both the concentration difference between the leaf intercellular air space and the ambient air outside the leaf boundary layer and to stomatal conductance, with the direction of the flux determined by the concentration gradient. In principle, any VOC can exhibit bi-directional fluxes. In order for uptake to occur, however, significant physico-chemical (e.g., solubility) or chemical sinks must be present in the leaf to reduce the internal gas phase concentration to levels below those in the surrounding atmosphere. Deposition of methanol to forest canopies has been reported (Karl et al., 2004, 2005), particularly at night. Since our experiments were carried out using zero air, we always observed emissions, and no one to our knowledge has examined compensation point behavior for methanol. It may 
be that the source strength of methanol production greatly exceeds any potential internal sinks (for example, methanol going into solution, oxidation of methanol to formaldehyde, or metabolism by methylotrophic bacteria) such that emission predominates and the compensation point is quite high. However, for mature leaves at low temperatures (and perhaps in the dark), methanol production decreases dramatically, and sinks may remain sufficiently high to lower the compensation point and allow methanol uptake, particularly if ambient concentrations are high. Experiments to determine the compensation point for methanol under varying light and temperature conditions are a logical next step in understanding controls over emissions.

\section{Conclusions}

Based on understanding gained at the level of the individual leaf, we plan to develop a canopy-scale model and compare model predictions with above-canopy methanol fluxes from a variety of ecosystems, measured using the eddy covariance technique. In this context, it is clear that our greatest uncertainty lies in the production term. The Niinemets-Reichstein model, in general, does an admirable job of explaining and predicting short-term deviations between rates of methanol production and rates of emission, arising from short-term non-equilibrium conditions following a perturbation such as a change in stomatal conductance. However, for those interested in the biosphere contribution to the total regional methanol source, such short-term fluctuations are irrelevant, and production rates are key. Short-term rates of methanol production clearly depend on temperature, increasing exponentially, at least during the day. For growing leaves, rates of production may change on hourly and daily time scales but can reach values at least an order of magnitude higher than in the same leaves after they reach maturity. In order to predict emissions at forest canopy or regional scales, the highest priority is additional enclosure measurements to establish average methanol production rates for a variety of plant species and/or above-canopy flux measurements to characterize a variety of important ecosystems. Also important will be studies to determine whether methanol production is reduced in darkness, and to characterize methanol compensation points and how they vary over time.

Acknowledgements. This research was supported in part through Interagency Agreement DW-49-92209501 between National Risk Management Laboratory of the U.S. Environmental Protection Agency and the National Science Foundation. The National Center for Atmospheric Research is operated by the University Corporation for Atmospheric Research under the sponsorship of the National Science Foundation. The helpful comments of two anonymous reviewers are also gratefully acknowledged.

Edited by: A. Neftel

\section{References}

Baker, B., Guenther, A., Greenberg, J., and Fall, R.: Canopy level fluxes of 2-methyl-3-buten-2-ol, acetone, and methanol by a portable relaxed eddy accumulation system, Environ. Sci. Technol., 35, 1701-1708, 2001.

Brunner, A., Ammann, C., Neftel, A., and Spirig, C.: Methanol exchange between grassland and the atmosphere, Biogeosciences, 4, 395-410, 2007, http://www.biogeosciences.net/4/395/2007/.

Custer, T. and Schade, G.: Methanol and acetaldehyde fluxes over ryegrass, Tellus B, 59, 673-684, 2007.

Das, M., Kang , D., Aneja, V. P., Lonneman, W., Cook, D. R., and Wesely, M. L.: Measurements of hydrocarbon air-surface exchange rates over maize, Atmos. Environ., 37, 2269-2277, 2003.

Fall, R. and Benson, A. A.: Leaf methanol - the simplest natural product from plants, Trends Plant Sci., 1, 296-301, 1996.

Fall, R. and Monson, R. K.: Isoprene emission rate and intercellular isoprene concentration as influenced by stomatal distribution and conductance, Plant Physiol., 100, 987-992, 1992.

Fukui, Y. and Doskey, P. V.: Air-surface exchange of nonmethane organic compounds at a grassland site: seasonal variations and stressed emissions, J. Geophys. Res., 103, 13 153-13 168, 1998.

Galbally, I. E. and Kirstine, W.: The production of methanol by flowering plants and the global cycle of methanol, J. Atmos. Chem., 43, 195-229, 2002.

Geron, C. D., Guenther, A., Greenberg, J., Loescher, H., Clark, D., and Baker, B.: Biogenic volatile organic compound emissions from a lowland tropical wet forest in Costa Rica, Atmos. Environ., 36, 3793-3802, 2002.

Gout, E., Aubert, S., Bligny, R., Rébeillé, F., Nonomura, A. R., Benson, A. A., and Douce, R.: Metabolism of methanol in plant cells, Carbon-13 nuclear magnetic resonance studies, Plant Physiol., 123, 287-296, 2000.

Guenther, A. B., Zimmerman, P. R., Harley, P. C., Monson, R. K., and Fall, R.: Isoprene and monoterpene emission rate variability: Model evaluations and sensitivity analyses, J. Geophys. Res., 98, 12 609-12 618, 1993.

Hanson D. R., Greenberg, J., Henry, B. E., and Kosciuch, E.: Proton transfer reaction mass spectrometry at high drift tube pressure, Int. J. Mass Spectrom., 223, 507-518, 2003.

Heikes, B. G., Chang, W., Pilson, M. E. Q., Swift, E., Singh, H. B., Guenther, A., Jacob, D. J., Field, B. D., Fall, R., Riemer, D., and Brand, L.: Atmospheric methanol budget and ocean implication, Global Biogeochem. Cy., 16, 1133, doi:10.1029/2002GB001895, 2002.

Holland, M. A. and Polacco, J. C.: PPFMs and other covert contaminants: is there more to plant physiology than just plant?, Annu. Rev. Plant Phys., 45, 197-209, 1994.

Holzinger, R., Sandoval-Soto, L., Rottenberger, S., Crutzen, P. J., and Kesselmeier, J.: Emissions of volatile organic compounds from Quercus ilex L. measured by Proton Transfer Reaction Mass Spectrometry under different environmental conditions, J. Geophys. Res., 105, 25 573-25 579, 2000.

Hüve, K., Christ, M. M., Kleist, E., Niinemets, Ü., Uerlings, R., Walter, A., and Wildt, J.: Simultaneous growth and emission measurements demonstrate an interactive control of methanol release by leaf expansion and stomata, J. Exp. Bot., 58, 1783-1793, 2007.

Jacob, D. J., Field, B. D., Li, Q., Blake, D. R., de Gouw, 
J., Warneke, C., Hansel, A., Wisthaler, A., Singh, H. B., and Guenther, A.: Global budget of methanol: constraints from atmospheric observations, J. Geophys. Res., 110, D08303, doi:10.1029/2004JD005172, 2005.

Karl, T., Guenther, A., Spirig, C., Hansel, A., and Fall, R.: Seasonal variation of biogenic VOC emissions above a mixed hardwood forest in northern Michigan, Geophys. Res. Lett., 30, 2186, doi:10.1029/2003GL018432, 2003.

Karl T., Harley, P., Guenther, A., Rasmussen, R., Baker, B., Jardine, K., and Nemitz, E.: The bi-directional exchange of oxygenated VOCs between a loblolly pine (Pinus taeda) plantation and the atmosphere, Atmos. Chem. Phys., 5, 3015-3031, 2005, http://www.atmos-chem-phys.net/5/3015/2005/.

Karl T., Potosnak, M., Guenther, A., Clark, D., Walker, J., Herric, J., and Geron, C.: Exchange processes of volatile organic compounds above a tropical rain forest: Implications for modeling tropospheric chemistry above dense vegetation, J. Geophys. Res., 109, D18306, doi:10.1029/2004JD004738, 2004.

Karl, T. G., Spirig, C., Rinne, J., Stroud, C., Prevost, P., Greenberg, J., Fall, R., and Guenther, A.: Virtual disjunct eddy covariance measurements of organic compound fluxes from a subalpine forest using proton transfer reaction mass spectrometry, Atmos. Chem. Phys., 2, 279-291, 2002,

http://www.atmos-chem-phys.net/2/279/2002/.

Keppler, F., Kalin, R. M., Harper, D. B., McRoberts, W. C., and Hamilton, J. T. G.: Carbon isotope anomaly in the major plant $\mathrm{C}_{1}$ pool and its global biogeochemical implications, Biogeosciences, 1, 123-131, 2004,

http://www.biogeosciences.net/1/123/2004/.

Kesselmeier, J.: Exchange of short-chain oxygenated volatile organic compounds (VOCs) between plants and the atmosphere: A comparison of field and laboratory studies, J. Atmos. Chem., 39, 219-233, 2001.

Kesselmeier, J. and Staudt, M.: Biogenic volatile organic compounds (VOC): An overview on emission, physiology and ecology, J. Atmos. Chem., 33, 23-88, 1999.

Kirstine, W., Galbally, I., Ye, Y., and Hooper, M.: Emissions of volatile organic compounds (including oxygenated species) from pasture, J. Geophys. Res., 103, 10 605-10 620, 1998.

Loreto, F., Ciccioli, P., Cecinato, A., Brancaleoni, E., Frattoni, M., Fabozzi, C., and Tricoli, D.: Evidence of the photosynthetic origin of monoterpenes emitted by Quercus ilex L. leaves by ${ }^{13} \mathrm{C}$ labeling, Plant Physiol., 110, 1317-1322, 1996.

MacDonald, R. C. and Fall, R.: Detection of substantial emissions of methanol from plants to the atmosphere, Atmos. Environ., 27, 1709-1713, 1993.

Nemecek-Marshall, M., MacDonald, R. C., Franzen, J. J., Wojciechowski, C. L., and Fall, R.: Methanol emission from leaves: Enzymatic detection of gas-phase methanol and relation of methanol fluxes to stomatal conductance and leaf development, Plant Physiol., 108, 1359-1368, 1995.

Niinemets, Ü. and Reichstein, M.: Controls on the emission of plant volatiles through stomata: Differential sensitivity of emission rates to stomatal closure explained, J. Geophys. Res., 108, 4208, doi:10.1029/2002JD002620, 2003a.

Niinemets, Ü. and Reichstein, M.: Controls on the emission of plant volatiles through stomata: A sensitivity analysis, J. Geophys. Res., 108, 4211, doi:10.1029/2002JD002626, 2003 b.

Niinemets, U., Reichstein, M., Staudt, M., Seufert, G., and Ten- hunen, J. D.: Stomatal constraints may affect emission of oxygenated monoterpenoids from the foliage of Pinus pinea, Plant Physiology, 130, 1371-1385, 2002.

Schade, G. W. and Goldstein, A. H.: Fluxes of oxygenated volatile organic compounds from a ponderosa pine plantation, J. Geophys. Res., 106, 3111-3123, 2001.

Seco, R., Peñuelas, J., and Filella, I.: Short-chain oxygenated VOCs: Emission and uptake by plants and atmospheric sources, sinks, and concentrations, Atmos. Environ., 41, 2477-2499, 2007.

Shim, C., Wang, Y., Singh, H. B., Blake, D. R., and Guenther, A. B.: Source characteristics of oxygenated volatile organic compounds and hydrogen cyanide, J. Geophys. Res., 112, D10305, doi:10.1029/2006JD007543, 2007.

Singh, H. B., Salas, L. J., Chatfield, R. B., et al.: Analysis of the atmospheric distribution, sources, and sinks of oxygenated volatile organic chemicals based on measurements over the Pacific during TRACE-P, J. Geophys. Res., 109, D15S07, doi:10.1029/2003JD003883, 2004.

Singh, H. B., Kanakidou, M., Crutzen P. J., and Jacob, D. J.: High concentrations and photochemical fate of oxygenated hydrocarbons in the global troposphere, Nature 378, 50-54, 1995.

Singh, H. B., Chen, Y., Tabazadeh, A., et al.: Distribution and fate of selected oxygenated organic species in the troposphere and lower stratosphere over the North Atlantic, J. Geophys. Res., 105, 3795-3805, 2000.

Spirig C., Neftel, A., Ammann, C., Dommen, J., Grabmer, W., Thielmann, A., Schaub, A., Beauchamp, J., Wisthaler, A., and Hansel, A.: Eddy covariance flux measurements of biogenic VOCs during ECHO 2003 using proton transfer reaction mass spectrometry, Atmos. Chem. Phys., 5, 465-481, 2005, http://www.atmos-chem-phys.net/5/465/2005/.

Tabazadeh, A., Yokelson, R. J., Singh, H. B., Hobbs, P. V., Crawford, J. H., and Iraci, L. T.: Heterogeneous chemistry on tropospheric clouds involving methanol, Geophys. Res. Lett., 31, L06114, doi:10.1029/2003GL018775, 2004.

Tie, X., Guenther, A., and Holland, E.: Biogenic methanol and its impacts on tropospheric oxidants, Geophys. Res. Lett., 30, 1881, doi:10.1029/2003GL017167, 2003.

von Caemmerer S. and Farquhar, G. D.: Some relationships between the biochemistry of photosynthesis and the gas exchange of leaves, Planta, 153, 376-387, 1981.

von Dahl, C. C., Havecker, M., Schlogl, R., and Baldwin, I. T.: Caterpillar-elicited methanol emission: a new signal in plantherbivore interactions?, Plant J., 46, 948-960, 2006.

von Kuhlmann, R., Lawrence, M. G., Crutzen, P. J., and Rasch, P. J.: A model for studies of tropospheric ozone and non-methane hydrocarbons: Model evaluation of ozone related species, J. Geophys. Res., 108, 4729, doi:10.1019/2002JD003348, 2003.

Walter A. and Schurr, U.: Dynamics of leaf and root growth: endogenous control versus environmental impact, Ann. Bot.London, 95, 891-900, 2005.

Warneke, C., Luxembourg, S. L., de Gouw, J. A., Rinne, H. J. I., Guenther, A. B., and Fall, R.: Disjunct eddy covariance measurements of oxygenated volatile organic compounds fluxes from an alfalfa field before and after cutting, J. Geophys. Res. 107, 4067, doi:10.1029/2001JD000594, 2002. 